\section{White Oak Dam \\ Stability Analysis}

Volume I

Syed B. Ahmed

\section{MANAGED BY}

MARTIN MARIETTA ENERGY SYSTEMS, INC.

FOR THE UNITED STATES

DEPARTMENT OF ENERGY 


\section{DISCLAIMER}

This report was prepared as an account of work sponsored by an agency of the United States Government. Neither the United States Govemment nor any agency thereof, nor any of their empioyees, makes any warranty, express or implied, or assumes any kgal liability or responsibility for the accuracy, completeness, or usefulness or any information, apparatus, product, or process disclosed, or represents that its use would not infringe privately owned rights. Reference herein to any specific commercial product, process, or service by trade name, trademart, manufacturer, or otherwise, does not necessarily constitute or imply its endorsement, recommendation, or favoring by the United States Government or any agency thereof. The views and opinions of authors expressed herein do not necessarily state or refiect those of the United States Government or any agency thereof. 


\section{DISCLAMMER}

Portions of this doecument may be illegible in electronic image products. Images are produced from the best available original document. 
X-OE-708

Central Engineering Services Division

\author{
WHITE OAK DAM \\ STABILTTY ANALYSIS
}

VOLUME I

Date Issued--January 1994

\author{
Prepared by \\ Central Engineering Services \\ Oak Ridge K-25 Site \\ Oak Ridge, Tennessee \\ operated by \\ MARTIN MARIETTA ENERGY SYSTEMS, INC. \\ for the \\ U.S. DEPARTMENT OF ENERGY \\ under contract DE-AC05-84OR21400
}




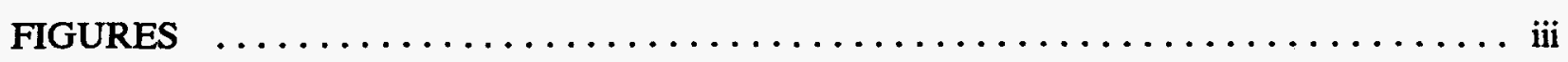

TABLES $\quad \ldots \ldots \ldots \ldots \ldots \ldots \ldots \ldots \ldots \ldots \ldots \ldots \ldots \ldots \ldots \ldots \ldots \ldots \ldots \ldots \ldots \ldots$ iv

EXECUTIVE SUMMARY $\ldots \ldots \ldots \ldots \ldots \ldots \ldots \ldots \ldots \ldots \ldots \ldots \ldots \ldots$

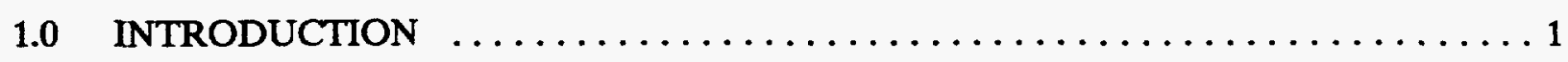

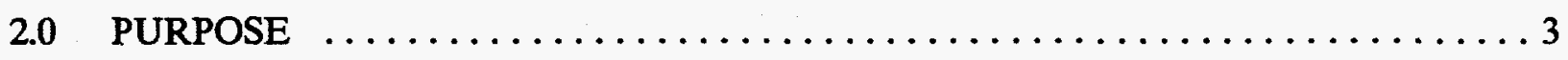

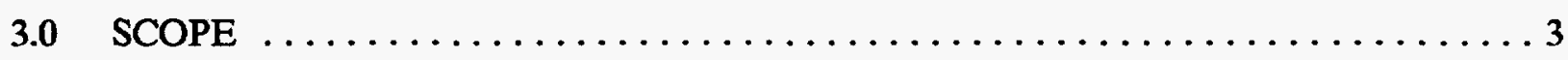

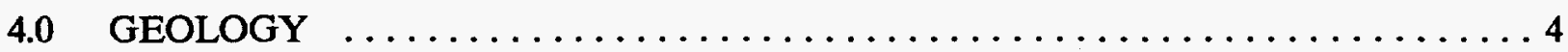

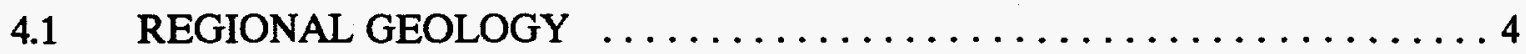

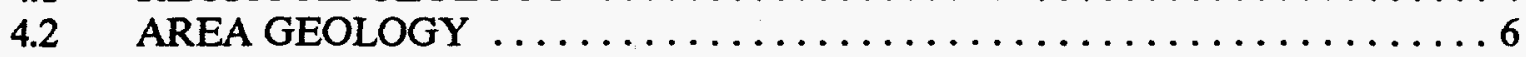

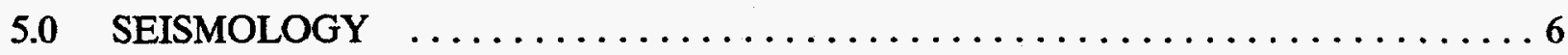

5.1 GENERAL SEISMOLOGY $\ldots \ldots \ldots \ldots \ldots \ldots \ldots \ldots \ldots \ldots \ldots \ldots \ldots \ldots \ldots$

5.2 EARTHQUAKES AFFECTING THE OAK RIDGE RESERVATION $\ldots \ldots 6$

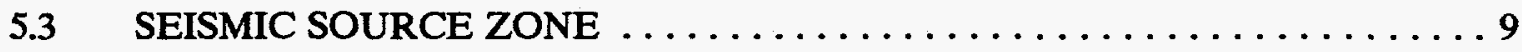

5.4 EVALUATION BASIS EARTHQUAKE $\ldots \ldots \ldots \ldots \ldots \ldots \ldots \ldots$

6.0 GEOTECHNICAL INVESTIGATIONS $\ldots \ldots \ldots \ldots \ldots \ldots \ldots \ldots \ldots$

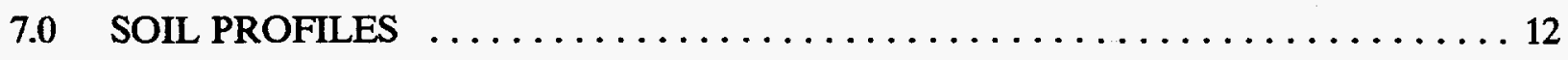

8.0 SOIL PROPERTIES $\ldots \ldots \ldots \ldots \ldots \ldots \ldots \ldots \ldots \ldots \ldots \ldots \ldots \ldots \ldots \ldots$

9.0 DAM HAZARD CLASSIFICATION $\ldots \ldots \ldots \ldots \ldots \ldots \ldots \ldots \ldots \ldots \ldots$

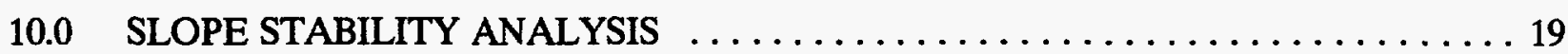

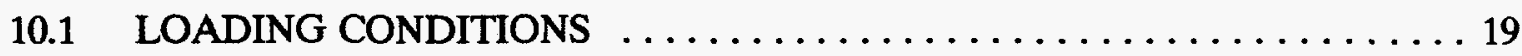

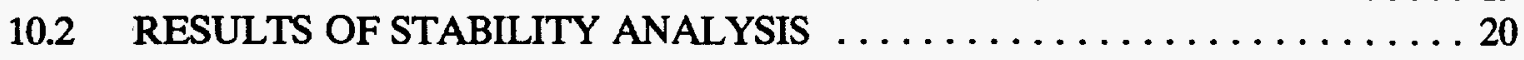

11.0 LIQUEFACTION ASSESSMENT $\ldots \ldots \ldots \ldots \ldots \ldots \ldots \ldots \ldots \ldots \ldots \ldots \ldots$

12.0 INSPECTION AND MAINTENANCE $\ldots \ldots \ldots \ldots \ldots \ldots \ldots \ldots \ldots \ldots \ldots$

12.1 PERIODIC INSPECTION PROGRAM $\ldots \ldots \ldots \ldots \ldots \ldots \ldots \ldots \ldots \ldots$

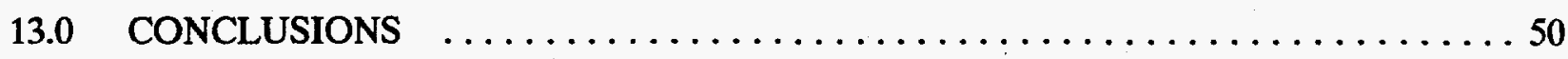

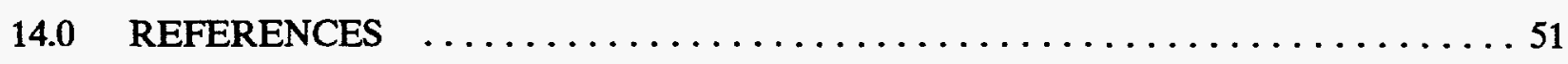

$15.0 \quad$ APPENDIX $\ldots \ldots \ldots \ldots \ldots \ldots \ldots \ldots \ldots \ldots \ldots \ldots \ldots \ldots$ SEE VOLUME II 


\section{FIGURES}

1. White Oak Dam Location Map $\ldots \ldots \ldots \ldots \ldots \ldots \ldots \ldots \ldots \ldots \ldots$

2. Simplified Geologic Map of the Oak Ridge Reservation Area $\ldots \ldots \ldots \ldots 5$

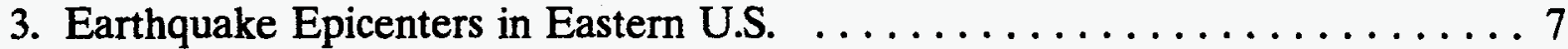

4. Earthquake Epicenters in East Tennessee $\ldots \ldots \ldots \ldots \ldots \ldots \ldots \ldots \ldots$

5. Borings Location Plan $\ldots \ldots \ldots \ldots \ldots \ldots \ldots \ldots \ldots \ldots \ldots \ldots \ldots \ldots$

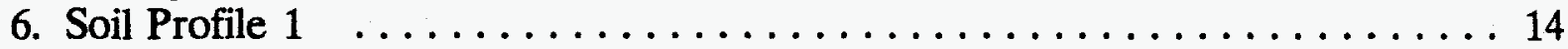

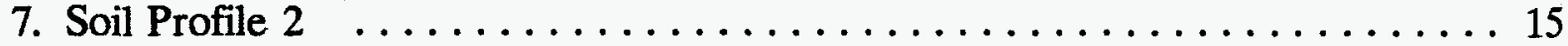

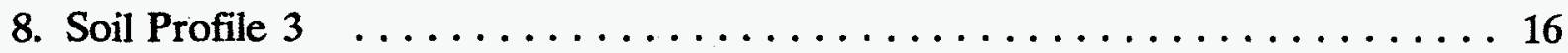

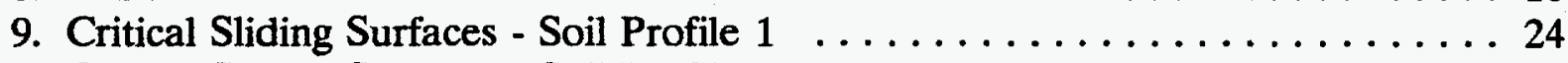

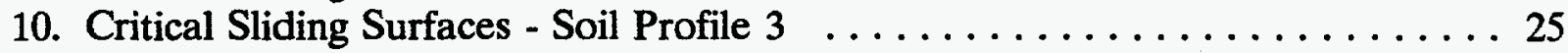

11. Limits On gradation Curves - Liquefiable and Nonliquifiable Soils . . . . . 27

12. Liquid Limit Vs. Natural Moisture Content .................. 29

13. Plasticity Chart ................................ 30

14-28. Number of Blows Vs. Cyclic Stress Ratio . . . . . . . . . . . . . 32-46

29. Control Monuments Location $\ldots \ldots \ldots \ldots \ldots \ldots \ldots \ldots \ldots \ldots \ldots$ 


\section{TABLES}

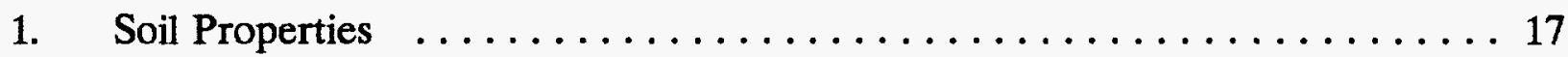

2. Summary - Slope Stability Analysis, Soil Profile $1 \ldots \ldots \ldots \ldots \ldots \ldots$

3. Summary - Slope Stability Analysis, Soil Profile $2 \ldots \ldots \ldots \ldots \ldots 22$

4. Summary - Slope stability analysis, Soil Profile $3 \ldots \ldots \ldots \ldots \ldots \ldots$ 


\section{EXECUTIVE SUMMARY}

A parametric study was conducted to evaluate the stability of the White Oak Dam (WOD) embankment and foundation. Slope stability analyses were performed for the upper and lower bound soil properties at three sections of the dam using the PCSTABL4 computer program. Minimum safety factors were calculated for the applicable seismic and static loading conditions. Liquefaction potential of the dam embankment and foundation soils during the seismic event was assessed by using simplified procedures.

The WOD is classified as a low hazard facility and the Evaluation Basis Earthquake (EBE) is defined as an earthquake with a magnitude of $m_{b}=5.6$ and a Peak Ground Acceleration (PGA) of $0.13 \mathrm{~g}$. This event is approximately equivalent to a Modified Mercalli Intensity of VI-VII. The $\mathrm{EBE}$ is used to perform the seismic evaluation for slope stability and liquefaction potential.

Results of the stability analyses and the liquefaction assessment lead to the conclusion that the White Oak Dam is safe and stable for the static and the seismic events defined in this study.

Ogden Environmental, at the request of MMES, has checked and verified the calculations for the critical loading conditions and performed a peer review of this report. Ogden has determined that the WOD is stable under the defined static and seismic loading conditions and the embankment materials are in general not susceptible to liquefaction. 


\subsection{INTRODUCTION}

White Oak Dam is an earth and rockfill structure originally constructed as a roadway embankment over White Oak Creek. The crest of the dam supports Tennessee 95, a two-laned, 40 $\mathrm{ft}$ wide, paved highway. The length of the dam is approximately $300 \mathrm{ft}$ and it's height varies from approximately $15 \mathrm{ft}$ to $25 \mathrm{ft}$. The dam is located approximately 0.6 miles above its confluence with the Clinch River (see Fig. 1). The surface area of the White Oak Lake is about 25 acres and the drainage area is on the order of 6 square miles. White Oak Creek watershed provide the primary surface water drainage for Oak Ridge National Laboratory (ORNL).

The White Oak Creek Embayment (WOCE) is a 0.6 miles long waterway located between the White Oak Dam and the Clinch River. Environmental Sampling Program has revealed the presence of radioactive contaminated surface sediments in the White Oak Lake and the White Oak Creek Embayment (WOCE). Due to the nature of the surface sediments it was decided to implement measures to control erosion and prevent transportation of contaminated materials downstream into the Clinch River. Consequently, a sediment retention WOCE structure was constructed in 1992 at the mouth of the White Oak Creek (confluence with the Clinch River). The WOCE structure is made up of diaphragm cells (of interlocking steel sheet pile panels) backfilled with selected material and topped with a permeable rock cap.

The cross-section of the White Oak Dam varies considerably in width. The downstream berm slope varies from $2 \mathrm{H}: 1 \mathrm{~V}$ to $3 \mathrm{H}: 1 \mathrm{~V}$, and the upstream slope ranges from $1.5 \mathrm{H}: 1 \mathrm{~V}$ to $3 \mathrm{H}: 1 \mathrm{~V}$.

The dam includes two outlets: (1) a box culvert, and (2) an emergency spillway.

(1) Box Culvert: A 16-ft wide by $12-\mathrm{ft}$ high concrete box culvert, was originally constructed in the early 1940's near the south end of the dam to carry White Oak Creek flow under the roadway. In 1943, a 36-ft by 13-ft steel sheet pile cofferdam was placed around the upstream culvert inlet to form a lake. Later, in 1959, the cofferdam was raised four feet making the nominal elevation of the crest of the cofferdam $753.9 \mathrm{ft}$. Twin sluice gates at the base of the cofferdam on the lake side were welded shut and are not functional.

(2) Emergency Spillway: An emergency spillway was constructed in 1983 on the north end of the dam to provide accurate stream flow measurement capability and to increase the spillway capacity of the dam. The spillway consists of twin lift gates, each 18-ft wide and approximately 9-ft high, which are operated by motor from an elevated catwalk. The gates are used to control the flow out of the lake and the reservoir level. The bottom or sill of the gates is at elevation 740.75 and the top of the gates at fully closed position is at elevation 749.90. When wide open, the gates bottoms are at elevation 750.92 and tops at 760.07 . In fully closed position, the gates would begin to be overtopped when the reservoir water reaches elevation 749.90. The updated hydrologic and spillway adequacy analysis show that the total spillway capacity of WOD remains classified as hydraulically "adequate" for the 100-year flood, regardless of the position of the gates; and "adequate" for the 0.10 PMF flood if the gates are wide open (Ref. 30).

Subsurface investigations were conducted during 1979-80, and 1987-88 to evaluate the embankment and foundation conditions at the dam site. 


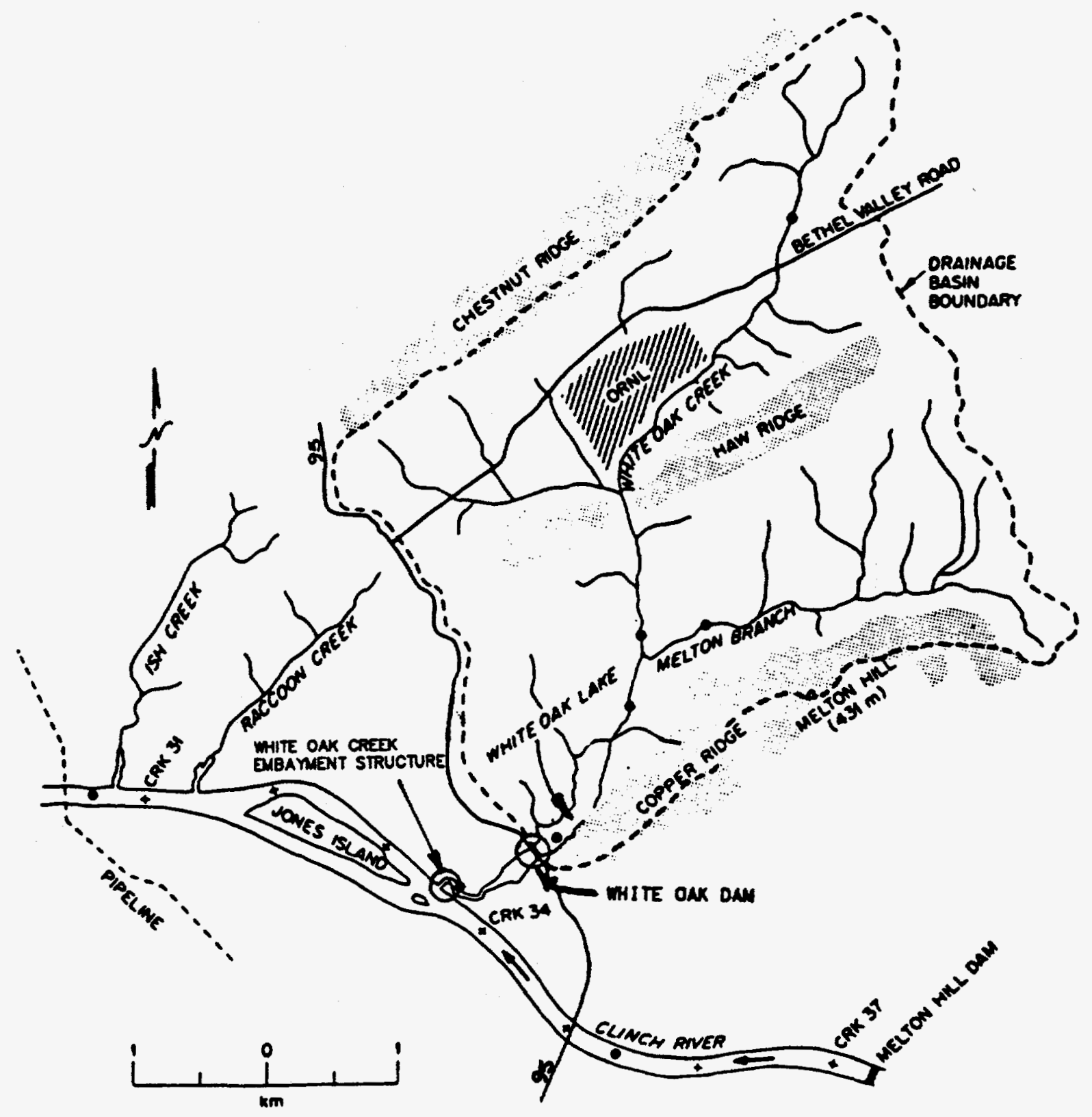

Figure I Map Showing White Oak Dam 
The 1979-80 investigation was performed by GEOTEK Engineering Company (Ref. 1). This investigation included 10 borings drilled at the locations shown on Fig. 5. Standard Penetration Test (SPT), and relatively undisturbed Shelby Tube samples of the embankment and foundation soils were collected. Laboratory tests were performed to determine the index properties, grain size distribution, unconfined compressive strength, consolidation and permeability of the soils.

The underlying rock formation was penetrated by use of NXM diamond core drilling. This investigation also included the installation of two piezometers to measure the groundwater levels. Additionally, GEOTEK made an evaluation of the box culvert discharge capacity. In summary, GEOTEK report raised concerns about the safety of the dam and the adequacy of the spillway (Box Culvert) capacity. As a result remedial measures were finalized through the intensive coordinating efforts by Union Carbide, TVA, TDOT, and R. L. Crisp, Jr. (Consultant). The remedial measures consisted of: (1) constructing a rockfill berm on the downstream face of the dam, and (2) installing a new Emergency Spillway. The rockfill berm and the Emergency Spillway were completed in 1980 and 1983 , respectively.

During 1987-88, Geologic Associates (Ref. 2) conducted a subsurface investigation of the subject dam. The exploratory program consisted of 12 borings drilled at the locations shown on Fig. 5 . The borings were drilled to a depth of between 20 and 30 feet and monitored for groundwater levels. SPT and shelby tube samples from embankment and foundation soil were collected. Laboratory tests were conducted for determining the index properties and shear strength of the soils.

\section{PURPOSE}

The purpose of this study is to evaluate the stability of the White Oak Dam embankment and foundation to assure that the dam maintains its integrity and remains functional during and after the design static and seismic events.

\subsection{SCOPE}

Stability analysis will be conducted using the PCSTABL4 computer program (Ref. 3). Soil profiles will be developed at three selected sections of the dam. A range of soil properties covering unit weights and shear strengths will be evaluated for each representative material encountered in the embankment and foundation of the dam. Applicable loading conditions for static and pseudostatic events will be defined. Seismic coefficient will be determined from the current design criteria based upon the hazard classification of the dam.

A parametric study will be performed for each soil profile using the upper bound and lower bound soil properties for the design static and pseudo-static events. Minimum safety factors will be calculated and compared against the safety factors desired by the Federal Energy Regulatory Commission (FERC) (Ref. 4).

Additionally, the embankment and foundation soils will be assessed for liquefaction potential using simplified procedures recommended by Seed, et al. (Ref. 20). These procedures are based upon index properties, grain size distribution, and correlation between SPT blow counts $(\mathrm{N})$ and Cyclic Stress Ratios (CSR) for a given magnitude and peak ground acceleration of earthquake. The design 
magnitude of earthquake and the peak ground acceleration will be determined from the specific seismic studies described in Section 5.4.

\subsection{GEOLOGY}

\subsection{REGIONAL GEOLOGY}

The Oak Ridge Reservation (ORR) is located in the western part of the Valley and Ridge Province at the narrowest part of the Appalachian foreland fold-thrust belt. Here the Valley and Ridge Province is dominated by several west-directed thrust faults that formed when the huge Blue Ridge sheet to the east pushed the Valley and Ridge sedimentary succession in front of it. The ORR contains a variety of geologic structures. The map-scale structure of the ORR is dominated by a uniform southeast dip of sedimentary layering interrupted only by the two large thrust faults, the Copper Creek and the White Oak Mountain faults, and the East Fork Ridge (and Pilot Knob) syncline in the footwall of the White Oak Mountain thrust. A simplified geologic map of the ORR is shown in Fig. 2.

The bedrock geology exposed in the ORR is composed entirely of sedimentary rocks that range in age from Early Cambrian to Early Mississippian. This stratigraphy formed as part of the early Paleozoic drift (ocean opening) succession. The carbonate bank was developed. Uplift and erosion of the carbonate bank occurred in early Middle Ordovician time forming the regional post-Knox unconfirmity, and the carbonate bank was reestablished during the middle Ordovician only to be destroyed later in the Ordovician by development of a clastic wedge in the Late Ordovician and Silurian. This was followed by erosion and formation of another unconfirmity, then by the deposition of the Upper Devonian-Early Carboniferous clastic wedge.

Nine major stratigraphic units have been recognized previously in the ORR: Rome Formation, Conasauga Group, Knox Group, Chickamauga Group, Reedsville Shale, Sequatchie Formation, Rockwood Formation, Chattanooga Shale, and Fort Payne Formation. Detailed studies of surface geology and core over the past decade have permitted subdivision of the Conasauga, Knox, and Chickamauga Groups. The Conasauga, and to a much lesser extent, the Knox and Chickamauga Groups, have served as the principal units for disposal of radionuclides and other waste materials in the ORR.

Outcrop-scale structures consist of inclined, faulted, and folded bedding, and joints. Joints (systematic fractures) are the most common structures present here, and several sets of joints with different orientations have been recognized. The dominant joint sets are oriented northeast and northwest, with lesser north-south and east-west sets. These structures are probably the most important in the ORR because they, along with bedding and local karst, form the conduit system that controls groundwater movement.

The mantle of unconsolidated residual materials, or regolith, derived by in situ weathering of bedrock, is composed mostly of silty clays and clayey silts. The water table typically is near the interface between regolith and bedrock. In a normal year, the water table is lowest during September-October and highest during February-March.

A detailed geology of the ORR is described in Ref. 8. 


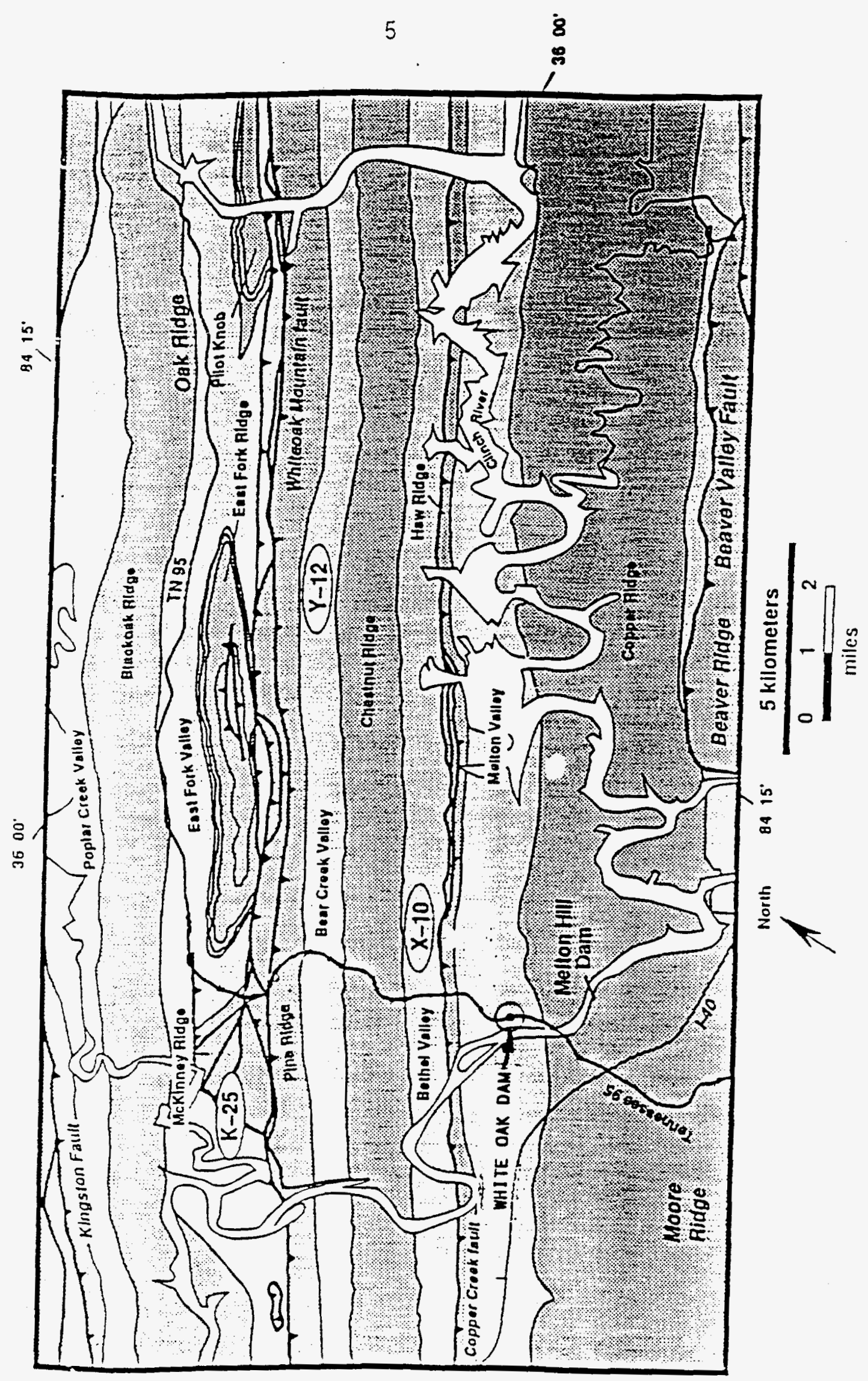

Figure 2 Simplified Geologic Map of the Oak Ridge Reservation 


\subsection{AREA GEOLOGY}

The White Oak Dam is located in the Valley and Ridge physiographic province which is comprised of generally NE-SW trending ridges held up by more resistant rocks such as sandstones, dolomites, quartzites; separated by parallel valleys underlain by weaker, more soluble limestones and more easily eroded shales. The dam is underlain by the Upper Cambrian Age Maynardville Formation which is comprised of medium bedded, blocky limestone. Generally, moderate weathering is present in the upper $15-20 \mathrm{ft}$ of this rock. This weathering is characteristically in the form of solutioning along bedding planes and joints. The limestone is generally bluish gray, fine-grained with nodules and ribbons of silt and dolomite. The total thickness of the Maynardville unit varies from 150 to $400 \mathrm{ft}$.

\subsection{SEISMOLOGY}

\subsection{GENERAL SEISMOLOGY}

Seismic activity in the vicinity of the ORR has primarily occurred in the Valley and Ridge Province, although some historical activity has occurred in the Cumberland Plateau. To the east of the Valley and Ridge province, a similar amount of seismic activity has occurred in the Blue Ridge province, and some scattered activity has occurred in the Piedmont province. Major historical activity has occurred in a northwesterly band of the Atlantic Coastal Plain province centered in South Carolina. The seismic activity described here is shown in Fig. 3. Additionally, the earthquake epicenters in east Tennessee, as recorded from 1977 to 1991 are shown on Fig. 4.

\subsection{EARTHQUAKES AFFECTING THE OAK RIDGE RESERVATION}

Of the earthquakes that are known to have occurred in the above regions, only three may have had any significant impact on the ORR. In 1886, the Charleston, South Carolina, earthquake occurred $520 \mathrm{~km}$ (325 miles) from the Reservation. This earthquake has been estimated to have had a Modified Mercalli Intensity (MMI) of X at the epicenter, and the effects at the ORR area have been estimated to have been an MMI of VI.

Following the 1886 Charleston, South Carolina, earthquake, an earthquake occurred in Giles County, Virginia, on May 31, 1897, $360 \mathrm{~km}$ (228 miles) from the ORR. This earthquake has been estimated to have an epicentral MMI from VII to VIII and at the ORR an MMI somewhere between $\mathrm{V}$ and VII.

The third earthquake was nearest the ORR, occurring just northwest of Knoxville on March 28, 1913, approximately $60 \mathrm{~km}$ (37 miles) from the Reservation. It has been estimated to have had an epicentral MMI of VII and an MMI of V to VI in the ORR.

The most recent significant earthquake to occur in the Appalachian area occurred on November 30,1973 , at Maryville, $34 \mathrm{~km}$ ( 21 miles) southeast of the ORR. This earthquake was estimated as having an epicentral MMI of VI and an MMI of IV in the ORR. Instrumental seismograph readings of this earthquake placed the magnitude at a value of $4.6 \mathrm{~m}_{\mathrm{b}}$. The recording instrument at the $\mathrm{Y}-12$ plant recorded a peak acceleration of $0.024 \mathrm{~g}$. No damage occurred at the Y-12 plant facilities from this earthquake. 


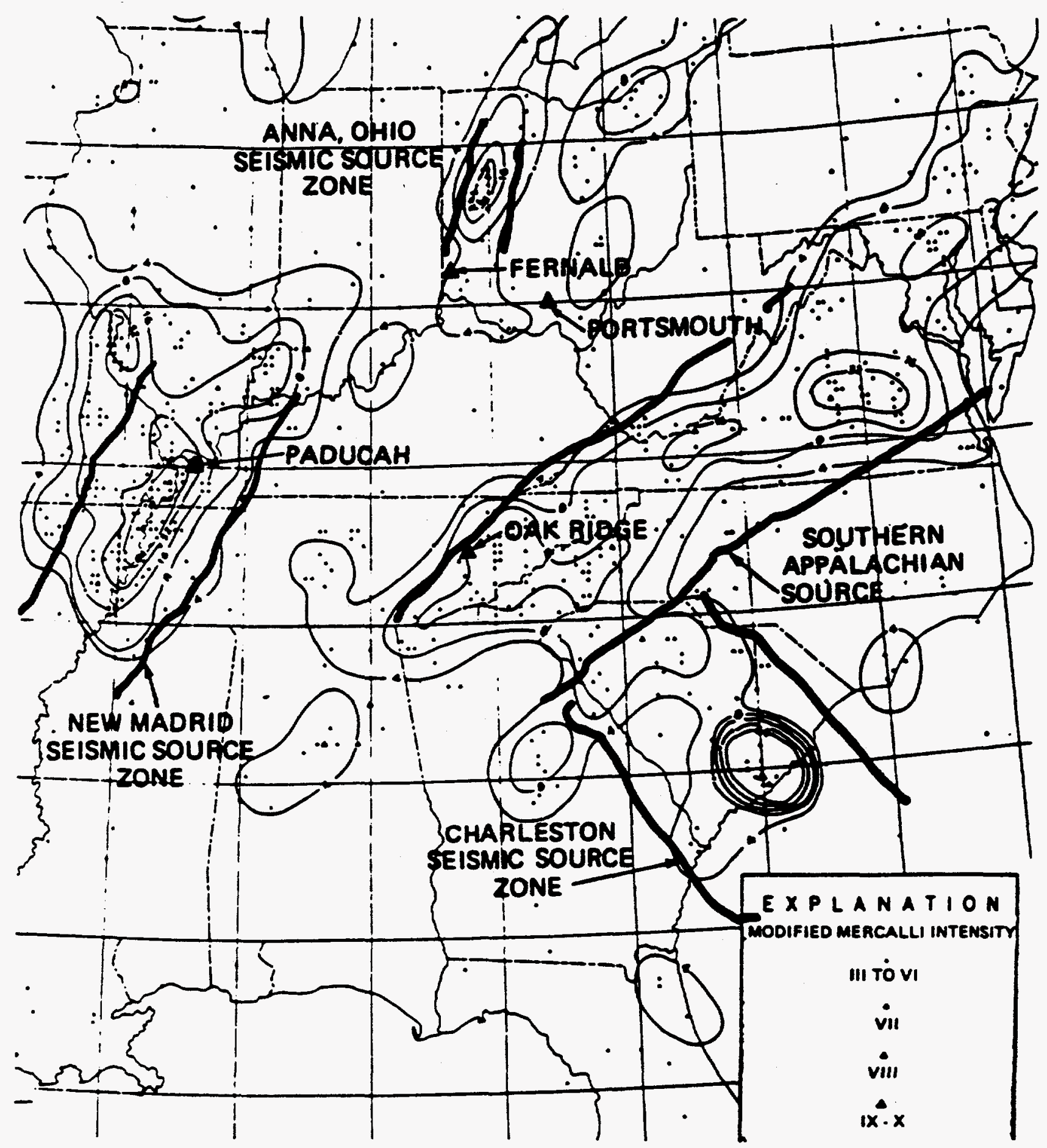

Figure 3 Earthquake Epicenters in Eastern U.S. 


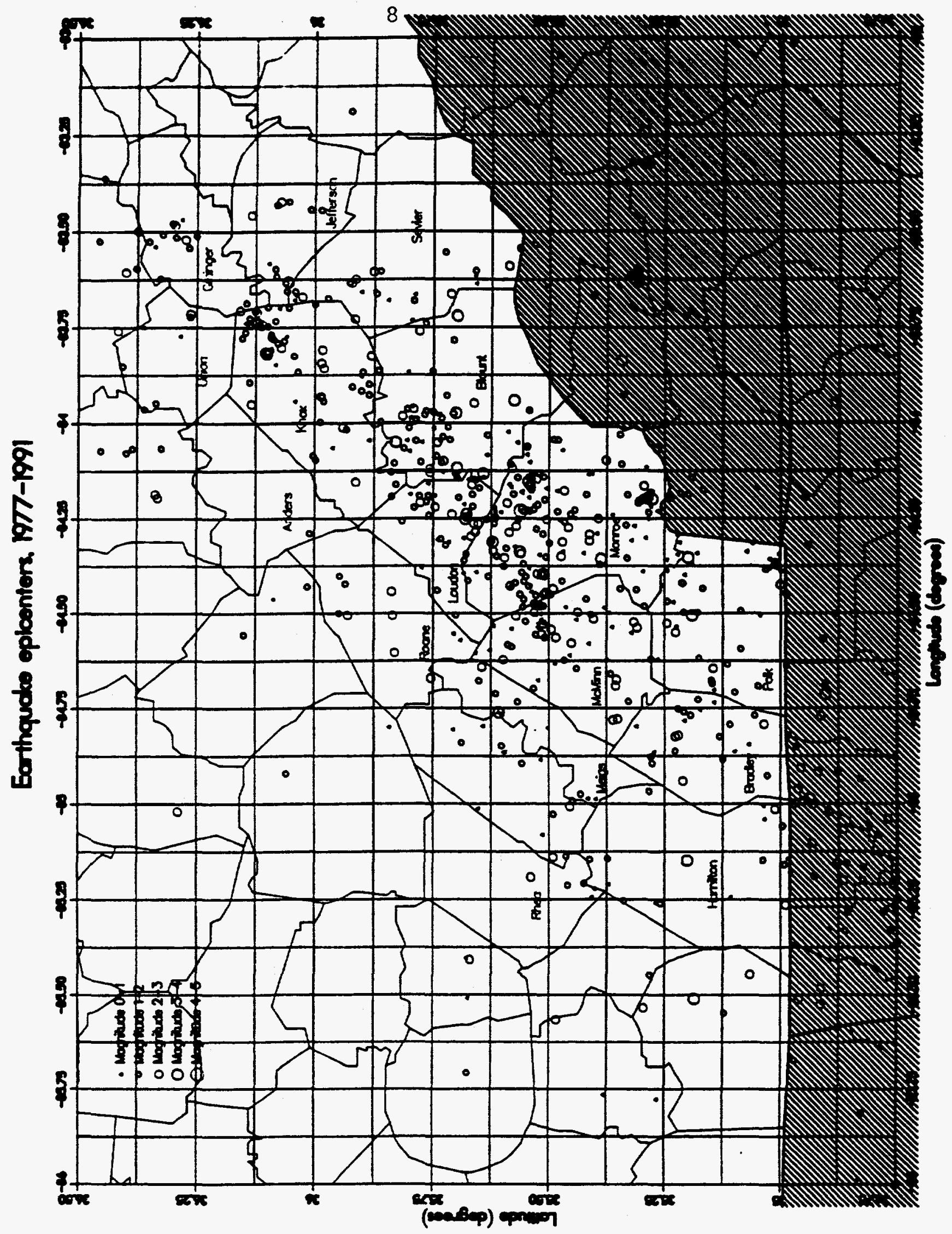

Figure 4 Earthquake Epicenters in East Tennessee, as Recorded on Seismic Network, 1977 - 1991 
Two other earthquakes are worthy of discussion that did not occur in the above provinces. The first is the series of earthquakes that occurred near New Madrid, Missouri, $450 \mathrm{~km}$ (280 miles) west of the area of ORR during the months of December 1811, January 1812, and February 1812. Three of these earthquakes have been estimated as having an epicentral MMI of X to XII and an MMI of $\mathrm{V}$ to VI at the ORR.

The second earthquake to discuss is significant because of it's recent occurrence, June 27, 1980. This earthquake occurred in Northern Kentucky approximately $290 \mathrm{~km}$ (180 miles) north of the ORR. The earthquake was estimated to have had an epicentral MMI of VII and a magnitude from instrumental records of $5.2 \mathrm{~m}_{\mathrm{b}}$. Some areas of the ORR experienced an MMI of I to II.

\subsection{SEISMIC SOURCE ZONE}

A recent seismic hazard study has indicated that the major potential for earthquake damage to the ORR is the seismic source zone of the Valley and Ridge province. Although there is considerable micro-earthquake activity occurring in the area, none of the activity can be attributed to known faulting.

\subsection{EVALUATION BASIS EARTHQUAKE}

The Evaluation Basis Earthquake (EBE) for the White Oak Dam has been determined using a combination of probabilistic and deterministic seismic hazard results from studies for the ORR. The seismic hazard studies are documented in Ref. 10-12. The studies were performed in accordance with DOE guidelines defined in Ref. 13 and 14. Reference 13 (UCRL-15910) defines four hazard categories for facilities for which the seismic hazard levels are needed. The hazard categories are defined as High, Moderate, Low, and General. The annual probabilities of exceedance for the seismic hazard for each category are $2 \times 10^{-4}, 1 \times 10^{-3}, 1 \times 10^{-3}$, and $2 \times 10^{-3}$, for High, Moderate, Low, and General, respectively. White Oak Dam has been determined to be in Low hazard category which defines the seismic hazard annual probability as $1 \times 10^{-3}$.

The probabilistic approaches used to define the seismic hazard levels are the Electric Power Research Institute (EPRI) (Ref. 26) and the Lawrence Livermore National Laboratory (LLNL) (Ref. 27) methodologies which were developed for the commercial nuclear power plants. The methodologies developed by EPRI and LLNL consider the following basic steps:

a. Identification of seismic sources (provinces) that contribute to the hazard at a site.

b. Estimation of seismicity parameters (i.e., activity rates, b-values, and maximum magnitude) for each source.

c. Selection of attenuation models to describe the level of ground motion as a function of earthquake magnitude and distance.

d. Calculation of the seismic hazard at a site on a source-by-source basis for alternative model parameters (e.g., ground motion attenuation models, estimates of maximum magnitude, etc.).

e. Based on input provided by experts, define for each site the combination of seismic sources or scenarios, that may be simultaneously active.

f. According to the source combinations specified by the experts, the seismic hazard at a site is evaluated in terms of the combined hazard contributed by each source in a combination. This produces combined hazard results. 
g. Aggregation of the seismic hazard results from the experts to determine the hazard at a site.

The development of the EPRI and LLNL methodologies, as explained in Ref. 26 and 27, relied on numerous experts to develop the various seismic sources, seismic catalogs, and seismicity recurrence data. The seismic sources and seismicity from these methodologies developed by EPRI and LLNL represent the state-of-the-art in defining the seismic hazard for a site. These methodologies define the seismic hazard considering all earthquakes (near field and far field). The contribution of near field and far field events, to the seismic hazard at a site, varies depending on the location of the site, seismicity of the region, and the annual probability of exceedance level of interest. From the probabilistic analyses, the dominant earthquake magnitudes and associated distances were then used deterministically to define the earthquake response spectra for the site which represents the seismic hazard at the annual probability of exceedance of $1 \times 10^{-3}$.

For ORR, the peak ground acceleration (PGA) for annual probability of exceedance of $1 \times 10^{-3}$ was determined to be $0.13 \mathrm{~g}$. The dominant magnitude and distance for the PGA were determined to be $\mathrm{m}_{\mathrm{b}}=5.6$ occurring at a distance of 38 kilometers. This is equivalent to a MMI of approximately VI-VII at the WOD site. These results indicate that the PGA for the seismic hazard with an annual probability of exceedance of $1 \times 10^{-3}$ is controlled by moderate magnitude near field events. This is expected considering the site location, seismic sources, and seismicity. Large magnitudes (near field or far field) will not contribute significantly to the seismic hazard PGA levels until much lower annual probabilities of exceedance are considered, i.e., the more frequent lower magnitude events contribute the most to the higher annual probabilities of exceedance and the less frequent higher magnitude events contribute more to the lower annual probabilities of exceedance.

Based on the above, White Oak Dam is classified as a low hazard facility, and the EBE is defined as an earthquake with a magnitude of $m_{b}=5.6$ occurring about 40 kilometers from the dam resulting in a PGA of $0.13 \mathrm{~g}$ at the dam site. This EBE is used to perform the seismic evaluations for slope stability and liquefaction potential.

\subsection{GEOTECHNICAL INVESTIGATIONS}

Geotechnical Investigations at the White Oak Dam site were conducted during 1979-80 and 198788 by GEOTEK Engineering Company (Ref. 1) and Geologic Associates (Ref. 2), respectively.

(1) GEOTEK drilled thirteen borings at the locations shown on Fig. 5. All borings were advanced into the embankment fill and the original foundation soil by means of a truck-mounted drilling rig using 4.5 in. diameter augers. The underlying rock formation was drilled by means of NXM diamond coring. Standard Penetration Tests (SPT) were conducted on the embankment and foundation soils in accordance with ASTM D 1568-67. The SPT soil samples were collected and the number of blow counts $(\mathrm{N})$ were recorded on the boring logs. Undisturbed soil samples were retrieved in 3-in diameter thin shelby tube samplers. Two Casagrande type piezometers were installed and ground water levels were measured.

Natural moisture contents and Atterberg limit tests were conducted on SPT and Shelby tube soil samples. Grain size analyses were performed on selected soil samples. In order to determine the strength of the soil, unconfined compression tests were performed on several undisturbed soil samples. Modified Proctor compaction tests (ASTM D 1557) were conducted on a combined soil 


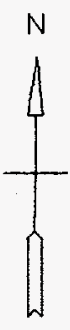

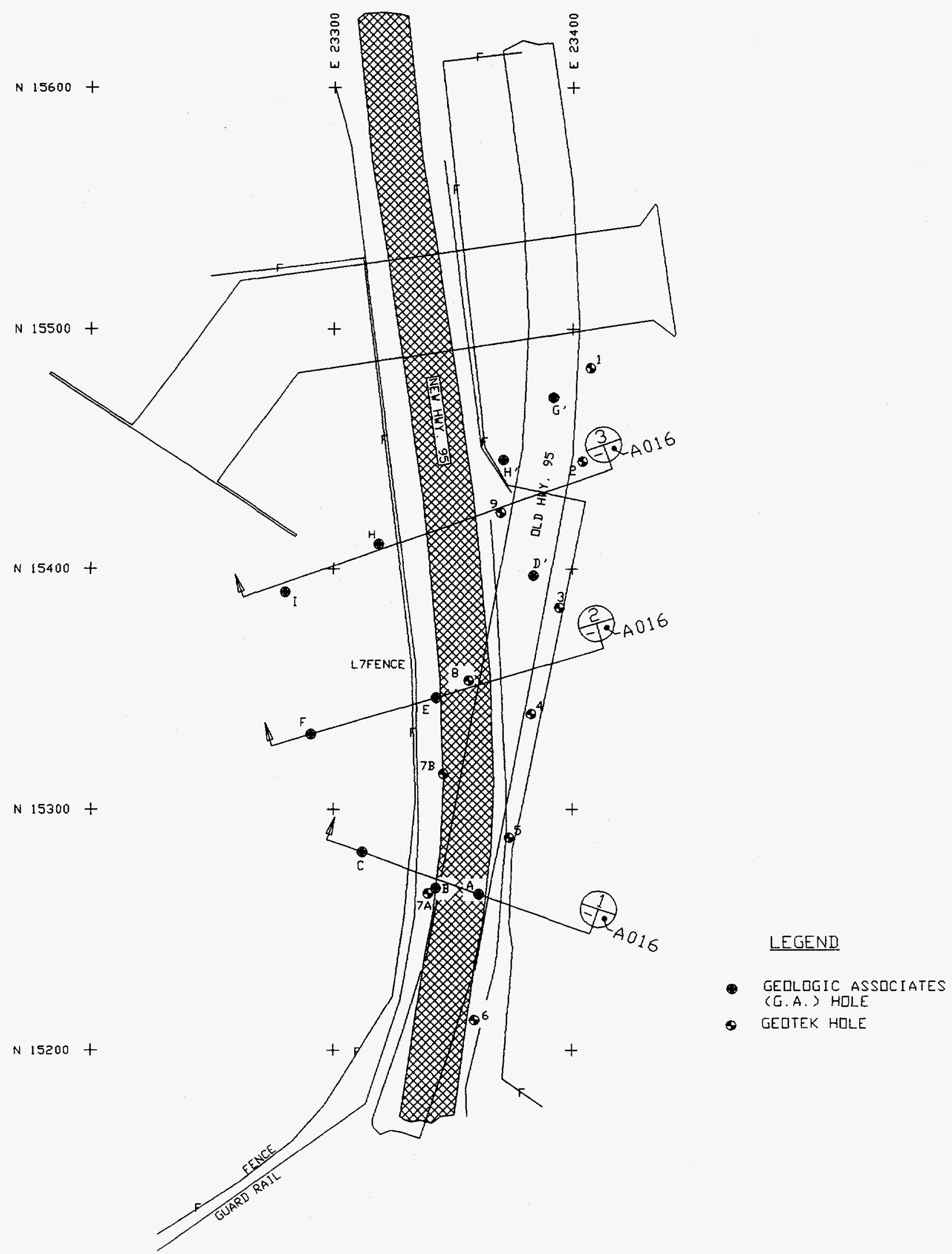

Figure 5 White Oak Dam Boring Location Plan, Scale: 1" $=60^{\prime}$ 
sample prepared by mixing representative soils from the borings. Degrees of compaction were determined by comparing the in situ dry unit weights obtained from undisturbed shelby tube samples with the maximum dry unit weight determined from ASTM D 1557 compaction test. Several consolidation tests (ASTM D 2435) were performed on undisturbed soil samples to determine the compressibility and permeability characteristics. Permeabilities were also determined in accordance with U.S. Army Corps of Engineers Specification EM-1110-1900.

This investigation revealed that the overburden soil consisted of soft to very stiff silty clays. The soils are generally mixed with weathered shale and chert fragments. The Atterberg limits tests indicate the soils to have low to medium plasticity. Zones of soft materials were encountered within the dam embankment and the original overburden in four borings. Although Geotek has reported the presence of soft material in excess of $\mathbf{1 5}$ feet under the northern end of the dam, it is unlikely that a layer of this thickness exists under the entire cross section.

The top of rock was encountered between elevations 720 and 728 , approximately. Rock was cored in eight borings. The length of coring varied from 5 to 20 feet. The rock cores indicated considerable drill breakage and grinding of the core due to limitations in available equipment and personnel cleared for working in the contaminated areas. The type of rock is generally shaley limestone.

The piezometers and observation wells records indicated that ground water levels are at elevation 743 to 745 . Water levels varied in the exploratory borings from depths of 9 to $15 \mathrm{ft}$. immediately after completion of the borings.

(2) Geologic Associates (GA) conducted an additional subsurface investigation during 1987-88. The GA exploratory program consisted of 12 borings drilled at the locations shown on Fig. 5 . The borings were drive-sampled in general accordance with ASTM D 1586. Relatively undisturbed soil samples were recovered at selected intervals by means of shelby tubes, in accordance with ASTM D 1587.

All of the samples were visually classified. Representative soil samples were tested for natural moisture content and Atterberg limits. Consolidated-undrained triaxial compression tests with pore pressure measurements were conducted on a shelby tube sample obtained from a depth of about 17 feet in bore hole $\mathrm{C}$.

The bore holes marked D', H', and G' were positioned in an attempt to locate and sample the soft zones identified in the GEOTEK investigation. Although some soft soils with $\mathrm{N}$ values less than 4 were identified, the thick soft zones described in the earlier GEOTEK investigation were not encountered.

The GA investigation revealed the overburden soils consisted of clayey silt and silty clay with varying amounts of shale fragments. Thickness of the fill soils ranged from 6 to 24 feet.

\subsection{SOIL PROFILES}

Soil profiles were developed at three locations shown on Fig. 5. The principal considerations for selecting these locations were to: (1) Capture the zones of soft soils; (2) Identify the lateral and vertical extent of the representative soil layers; and (3) Define the subsoil conditions at the north and south ends, and the middle of the dam. 
Equal weight was given to the Geotek and the GA data in developing the soil profiles. Soil layers were classified as soft, medium, stiff, and very stiff on the basis of their consistencies. Unconfined compressive strength, degree of compaction, and $\mathrm{N}$ values were used to determine the consistencies.

Figures 6, 7, and 8 present soil profiles 1, 2, and 3, respectively. The dimensions and details of rockfill berms shown on the profiles are taken from the as-built drawings. In some instances, boring data have been interpolated and projected on the cross sections to define the soil profiles as thoroughly as possible.

\section{SOIL PROFILE 1}

This profile (Fig. 6) was developed on the basis of geotechnical data from borings C, 7A, B, A', and interpolation between borings 5 and 6 . The stratigraphy mainly consists of medium and stiff silty clays. A few isolated pockets of soft clay and organic matter were encountered. The downstream rockfill berm is underlain by medium silty clay. Top of rock is encountered at El. $730_{ \pm}$.

\section{SOIL PROFILE 2}

Subsurface data from borings 3, 4, 8, E, and F were used to develop the stratigraphy shown in Fig. 7. Silty clays with soft, medium, and stiff consistencies are present at the central section of the dam. On the downstream side, the soft soil is laterally confined by the rockfill berm. Top of rock is interpreted to be fairly uniform elevation $730_{ \pm}$.

\section{SOIL PROFILE 3}

Borings $9, \mathrm{H}, \mathrm{I}$, and projections of borings 2 and $\mathrm{H}^{\prime}$ were essentially used to develop soil profile 3 shown on Fig. 8. The overburden soil consists of medium silty clay underlain by soft soil. At the central section stiff soil underlies the soft material. Rock is encountered at elevations varying from $730 \pm$ to $734 \pm$.

\subsection{SOIL PROPERTIES}

Table 1 presents the soil properties used in the slope stability analysis of the White Oak Dam. These properties were developed based on the laboratory data from the two previous investigations of the dam site (Ref. 1 and 2) and a review of regional data collected by the Tennessee Valley Authority (Ref. 15).

The rockfill berm properties and the foundation rock properties were obtained from an earlier analysis by Dr. Eric Drumm of the University of Tennessee (Ref. 16). For soft silty clay, the consolidated-undrained (C-U), and the consolidated-drained (C-D) parameters of cohesion were directly obtained from the unconfined compression tests previously conducted by Geotek Engineering (Ref. 1).

The cohesion and angle of internal friction shown for the medium silty clay were developed from the triaxial tests performed by GA (Ref. 2). Earlier values developed by Dr. Drumm used the stress 


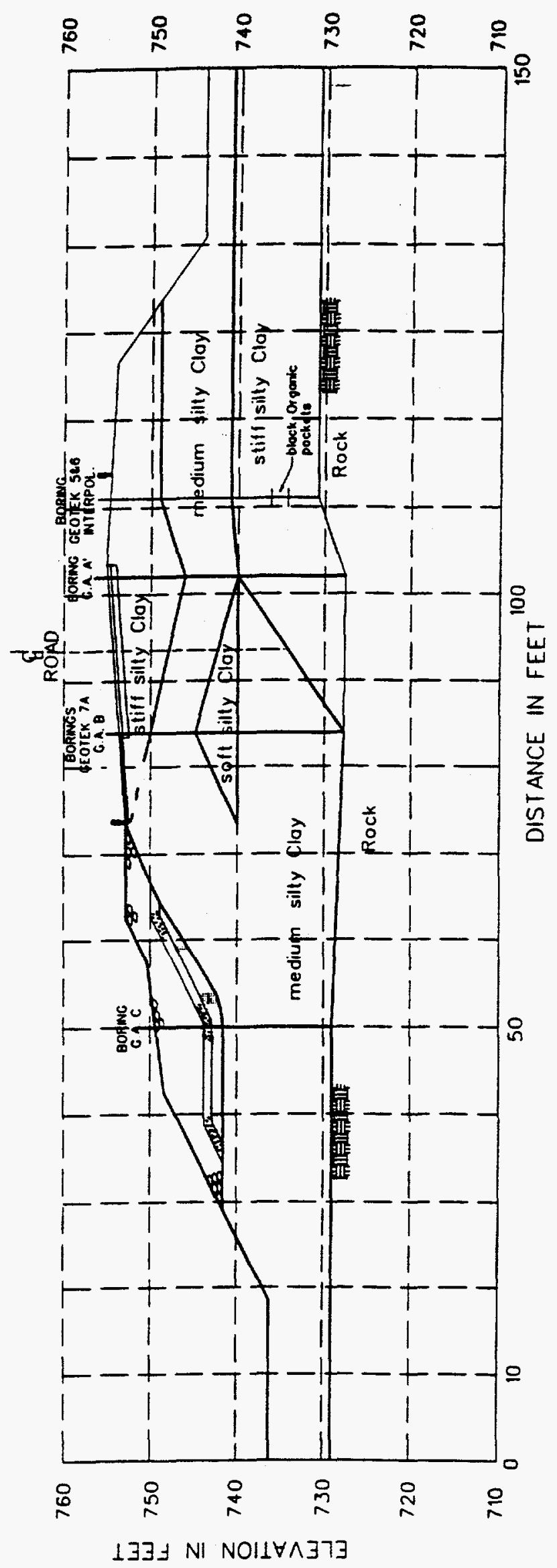

Figure 6 soil profile 1-1 


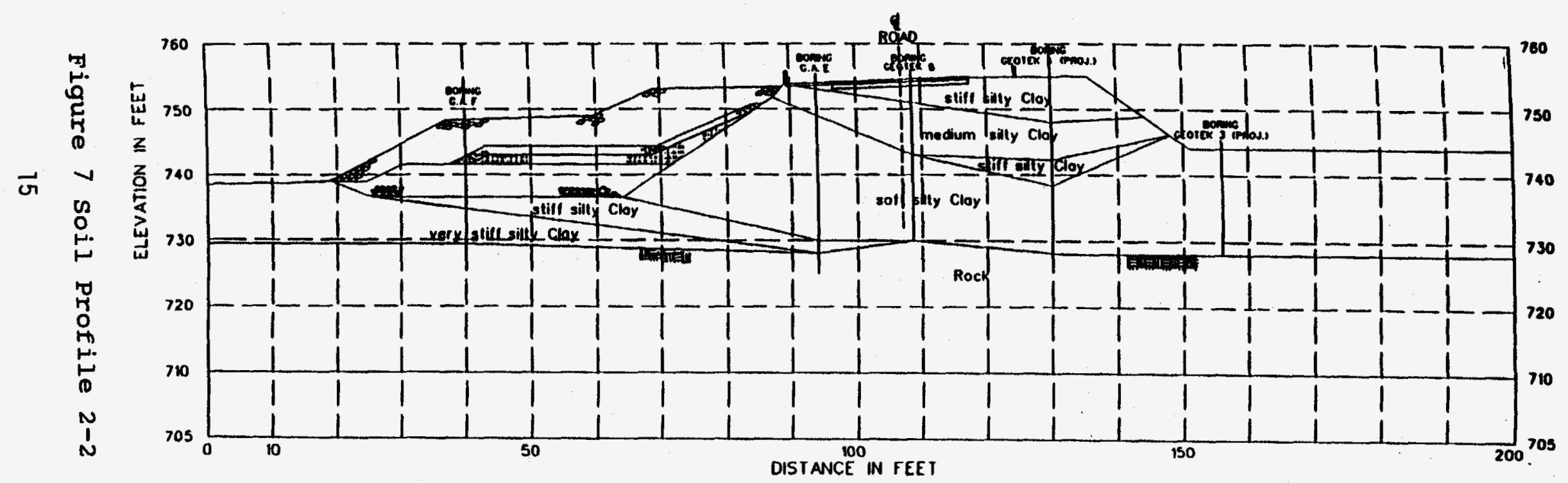




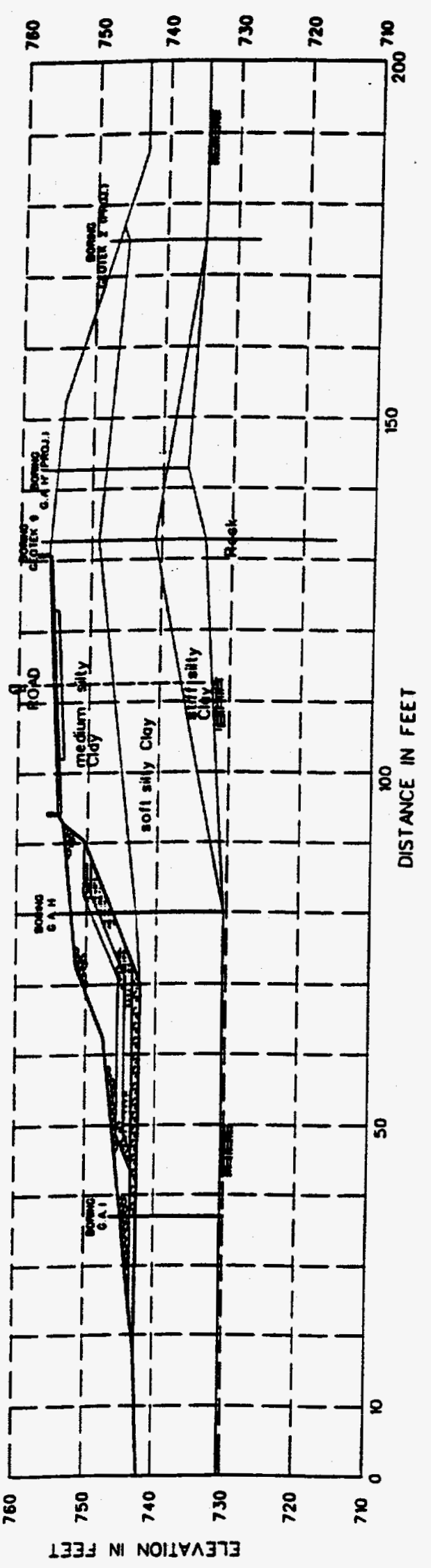

Figure 8 Soil Profile 3-3 
TABLE 1 SOIL PROPERTIES

\begin{tabular}{|c|c|c|c|c|c|c|}
\hline \multirow[b]{2}{*}{ SOIL } & \multirow{2}{*}{$\begin{array}{l}\text { TOTA } \\
\text { UNIT WEIGHT } \\
\text { (PCF) }\end{array}$} & \multirow[b]{2}{*}{$\begin{array}{c}\text { SATURATED } \\
\text { UNIT WEEGHT } \\
\text { (PCF) }\end{array}$} & \multicolumn{2}{|c|}{$\begin{array}{l}\text { CONSOLIDATED - UNDRAINED } \\
\text { SHEAR STRENGTH }\end{array}$} & \multicolumn{2}{|c|}{$\begin{array}{c}\text { CONSOLIDATED - DRANED } \\
\text { SHEAR STRENGTH }\end{array}$} \\
\hline & & & \begin{tabular}{|c|} 
ANGLE OF \\
INTERNAL FRICTION \\
DEG
\end{tabular} & $\begin{array}{c}\text { COHESION } \\
\text { PSF }\end{array}$ & $\begin{array}{c}\text { ANGLE OF } \\
\text { NTTERNAL FRICTION } \\
\text { (DEG) }\end{array}$ & $\begin{array}{l}\text { COHESION } \\
\text { (PSF) }\end{array}$ \\
\hline $\begin{array}{l}\text { SOFT SILTY } \\
\text { CLAY }\end{array}$ & 117 & 120 & 0 & $285-425$ & 0 & $285-425$ \\
\hline$\underset{\text { CLAY SILTY }}{\text { MEDNM }}$ & 119 & 125 & 16 & $225-260$ & 29-30 & $0-70$ \\
\hline $\begin{array}{l}\text { STIFF SULTY } \\
\text { CLAY }\end{array}$ & 122 & 127 & 15 & $1100-1650$ & $27-32$ & $200-300$ \\
\hline $\begin{array}{l}\text { VERY STIFF } \\
\text { SILTY CLAYY }\end{array}$ & 127 & 129 & 15 & 1650 & 32 & 300 \\
\hline ROCKFLL & 135 & 135 & 35 & 0 & 35 & 0 \\
\hline $\begin{array}{l}\text { FOUNDATION } \\
\text { ROCK }\end{array}$ & 165 & 165 & 35 & 10000 & 35 & 10000 \\
\hline
\end{tabular}


path method. The triaxial data was replotted and Mohr's circles were used to determine a range of appropriate values for cohesion and the angle of internal friction (see Appendix A1). The values of cohesion and angle of internal friction for the stiff and very stiff silty clays were developed from the TVA regional data (Ref. 15) for similar soils based on index properties, and unit weights.

\subsection{DAM HAZARD CLASSIFICATION}

A hazard screening and facility categorization for White Oak Dam has been performed (Ref 32). The purpose of these activities is to group facilities and processes according to the magnitude of their hazards. This hazard classification process is restricted to human safety issues only.

The first step of the hazard screening process is preliminary hazard screening. This is a sorting process used to screen obviously benign facilities or processes from unnecessarily detailed hazard screening analysis. The preliminary hazard screening may be by passed if it is apparent that a more detailed analysis is needed. Since there is currently a significant amount of radionuclides in the sediments of White Oak Lake a more detailed analysis is needed and the preliminary hazard screening will not be performed.

Facilities or processes that are not eliminated by the preliminary hazard screening are divided into functional systems and then subjected to an initial event selection which uses a modified Hazard and Operability technique or a failure Modes and Effects Analysis to generate calculations which assign the system an initial hazard classification. At this point, a preliminary hazard identification matrix form must be filled out (see Appendix A4).

Initial event selection for the White Oak Dam facility results from the obvious potential hazard resulting from a dam failure. At least one credible (physically possible) event needs to be postulated to support the event selection. For the White Oak Lake Dam failure, two events can be postulated, an earthquake or a major flood event. At this point in the analysis it is not expected that the probability of the initiating event be quantified. Based on this process, a preliminary hazard analysis worksheet has been filled out (see Appendix A4).

The next step is scenario development which is used to determine the bounding scenario and allow for the consequences of the scenario to be evaluated. The bounding scenario is defined as that which produces the most severe consequences to the on-site or off-site personnel. Calculations are then performed based on the assumptions in the bounding scenario. This scenario and resulting dose calculations have already been developed and documented (see Appendix A4). Using the more conservative second scenario developed, the maximum dose rate would be $63 \mathrm{mrem} / \mathrm{year}$. This estimate is based on loosing $100 \%$ of the approximately 400 Curie (Ci) of Cs-137 in the White Oak Lake sediments. More recent studies have suggested that $100-300 \mathrm{Ci}$ would probably be lost through a dam failure. Using the same exposure assumptions, this would result in conservative dose estimates of 15-45 mrem/year. Credit for additional dilution, sediment partitioning, and the construction of White Oak Creek Embayment sediment structure have not been factored in for these screening calculations. These calculations have been performed to give a general idea of the consequences of the relative magnitude of a dam failure, it does not imply that these exposures are expected to occur, or if they did, that they would be acceptable. 
On the basis of these results, an initial hazard classification can be assigned based on one of three categories; low, medium, or high. Table 2.6-4 in CSET-2 (Ref. 17) defines exposure levels of the order calculated for the White Oak Dam failure scenario as comprising negligible health effects. This results in an initial hazard classification of low for this scenario.

The final step in the hazard screening process is obtaining consensus. The installation management has reviewed and concurred with the low final hazard classification recommendations to ensure that the results are reasonable and to ensure management awareness of hazard classification.

\subsection{SLOPE STABUITY ANALYSIS}

A limiting equilibrium slope stability analysis was performed on soil profiles 1,2 , and 3 with the aid of a computer program using circular arc surfaces Modified Bishop method. The computer program used is entitled STABL4 and was developed during the Joint Highway Research Project HRP-79-6 by Purdue University and the Indiana State Highway Commission (Ref. 3). This computer program was used to determine the safety factors of both static and pseudo-static conditions of the embankment slope. For a given cross section of the dam, the analysis investigates a number of potential sliding surfaces and identifies the critical sliding surface with the lowest factor of safety. The factor of safety is defined as the ratio of the forces or the moments resisting movement of the mass above the sliding surface, to the forces or moments tending to cause movement. Thus, conditions with a factor of safety greater than 1 indicates that the forces or moments resisting movements are greater than those tending to cause movement and the surface investigated is stable. A factor of safety equal to 1 indicates that the surface is currently under conditions of equilibrium and is at incipient failure. Values less than 1 imply that the surface is unstable and can not exist as defined.

\subsection{LOADING CONDITIONS}

Three types of laboratory triaxial tests are generally used to represent loading conditions for determining the slope stability of dams.

(1) Unconsolidated-Undrained (Q)

(2) Consolidated-Undrained (R), and

(3) Consolidated-Drained (S).

(1) Unconsolidated-Undrained (Q): This test attempts to simulate the conditions in which pore water pressures develop in fine-grained soils during placement and compaction of fill. $Q$ test data are used in slope stability analyses for non-pervious soils during construction and end of construction loading conditions. Since White Oak Dam was constructed several years ago, the $Q$ loading condition is not applicable. Therefore, slope stability analysis was not performed for the $Q$ case.

(2) Consolidated-Undrained ( $R$ ): This test simulates the conditions where soils are fully consolidated under one set of stresses and then are subjected to a stress change without time for stress-induced consolidation to take place. $\mathbf{R}$ strengths are generally applicable in slope stability analyses investigating rapid drawdown and earthquake loading conditions. For soil profiles 1,2 , and $3, \mathrm{R}$ strength analyses have been performed for the following loading conditions: 
(i) Rapid drawdown from Maximum Pool Elevation $755.0 \mathrm{ft}$ - Upstream Slope

(ii) Rapid drawdown from Top of Gate Elevation $750.0 \mathrm{ft}$ - Upstream Slope

(iii) Seismic event, Normal Pool Elevation $744.0 \mathrm{ft}$ - Downstream Slope

(3) Consolidated-Drained (S): S strengths are appropriate for free draining soils in which pore pressures do not develop and for consolidated fine grained soils where the rate of shear stress application is so slow that drainage can take place. S strengths are applicable for investigating long term (steady seepage) stability analyses. For soil profiles 1,2 , and 3, S strength analyses have been performed for the following loading conditions:

i) Steady Seepage, Maximum Pool Elevation $755.0 \mathrm{ft}$ - Downstream Slope

ii) Steady Seepage, Top of Gate Elevation $750.0 \mathrm{ft}$ - Downstream Slope

It may be noted that the steady seepage (long term) loading conditions are simulated by conducting the analysis with the reservoir at the highest levels that may persist over a long period of time which are extremely conservative cases. Additionally, the rapid drawdown from maximum pool and the top of the gate used in the analyses represent overly conservative loading cases versus the more likely drawdown from a normal pool elevation of 744.0.

The seismic or earthquake condition was simulated in a pseudostatic analysis with a horizontal acceleration of $0.13 \mathrm{~g}$ under normal pool conditions. The Committee on the Safety of Existing Dams (National Research Council, 1983), has suggested that a pseudostatic analysis is usually sufficient for evaluating the stability of dams built of cohesive materials on stable foundations.

According to FERC (Ref. 4) "All confirmed low hazard potential projects may be evaluated by the pseudostatic method using the seismic coefficient assigned to the seismic zone the project is in". White Oak Dam is located in Zone 2 with a seismic coefficient of 0.10 which is lower than the (EBE) $\mathrm{PGA}=0.13 \mathrm{~g}$ used in the stability analysis. Therefore the pseudostatic method using the seismic coefficient of $0.13 \mathrm{~g}$ is more conservative than FERC requirements.

\subsection{RESULTS OF STABILTY ANALYSIS}

The results of the slope stability analysis for the three soil profiles for all the loading conditions described in section 10.1 are summarized in Tables 2, 3, and 4. The computer printouts for the critical loading conditions are presented in Appendix A-3. The summary of results includes the calculated minimum safety factors for lower bound and upper bound soil properties. Also indicated in these Tables are the minimum safety factors desired by FERC (Ref. 4). The calculated safety factors are rounded to the first decimal place. Shallow sliding surfaces which will have no impact on the structural integrity of the slope are not considered. The critical sliding surfaces corresponding to the minimum safety factors for profiles 1 and 3 are shown on Fig. 9 and 10. The results show that using the upper bound soil properties, the minimum safety factors exceeded the FERC desired safety factors for all loading conditions at each soil profile. When the lower bound properties were applied, the minimum safety factors exceeded the FERC desired safety factors for: (1) Four out of five loading conditions for soil profile 1; (2) All loading conditions for soil profile 2; and (3) Four out of five loading conditions for soil profile 3. For the two loading cases i.e. downstream slope at soil 
TABLE 2 SUMMARY - SLOPE STABILITY ANALYSIS

SOIL PROFILE 1

\begin{tabular}{||c|c|c|c|c||}
\hline \multirow{2}{*}{ LOADING CONDITIONS } & \multicolumn{2}{|c|}{ MINIMUM FACTOR OF SAFETY } & \multirow{2}{*}{ COMMENTS } \\
\cline { 2 - 5 } & $\begin{array}{c}\text { LOWER BOUND } \\
\text { PROPERTIES }\end{array}$ & $\begin{array}{c}\text { UPPER BOUND } \\
\text { PROPERTIES }\end{array}$ & FERC & \multirow{2}{*}{ Acceptable } \\
\hline \hline $\begin{array}{l}\text { Upstream Slope } \\
\text { Rapid Drawdown } \\
\text { from Max Pool (elev =755 ft) }\end{array}$ & 2.0 & 2.4 & 1.1 & \multirow{2}{*}{ Acceptable } \\
\hline $\begin{array}{l}\text { Upstream Slope } \\
\text { Rapid Drawdown } \\
\text { from Top of Gate (elev }=750 \mathrm{ft})\end{array}$ & 2.1 & 2.5 & 1.2 & Acceptable \\
\hline $\begin{array}{l}\text { Downstream Slope } \\
\text { Steady Seepage } \\
\text { at Max Pool (elev }=755 \mathrm{ft})\end{array}$ & 1.4 & 1.6 & 1.4 & Acceptable \\
\hline $\begin{array}{l}\text { Downstream Slope } \\
\text { Steady Seepage } \\
\text { at Top of Gate (elev }=750 \mathrm{ft})\end{array}$ & 1.4 & 1.6 & 1.5 & Acceptable \\
\hline $\begin{array}{l}\text { Downstream Slope } \\
\text { Normal Pool (elev }=744 \mathrm{ft}) \\
\text { Seismic 0.13g(H) }\end{array}$ & 1.1 & 1.2 & 1.0 & \\
\hline
\end{tabular}


TABLE 3 SUMMARY - SLOPE STABILITY ANALYSIS

SOIL PROFILE 2

\begin{tabular}{||l|c|c|c|c||}
\hline \multirow{2}{*}{ LOADING CONDITIONS } & \multicolumn{3}{|c|}{ MINIMUM FACTOR OF SAFETY } & \multirow{2}{*}{ COMMENTS } \\
\cline { 2 - 5 } & $\begin{array}{c}\text { LOWER BOUND } \\
\text { PROPERTIES }\end{array}$ & $\begin{array}{c}\text { UPPER BOUND } \\
\text { PROPERTIES }\end{array}$ & FERC & \multirow{2}{*}{ Acceptable } \\
\hline $\begin{array}{l}\text { Upstream Slope } \\
\text { Rapid Drawdown } \\
\text { from Max Pool (elev =755 ft) }\end{array}$ & 1.3 & 1.9 & 1.1 & \multirow{2}{*}{ Acceptable } \\
\hline $\begin{array}{l}\text { Upstream Slope } \\
\text { Rapid Drawdown } \\
\text { from Top of Gate (elev }=750 \mathrm{ft})\end{array}$ & 1.4 & 2.0 & 1.2 & Acceptable \\
\hline $\begin{array}{l}\text { Downstream Slope } \\
\text { Steady Seepage } \\
\text { at Max Pool (elev }=755 \mathrm{ft})\end{array}$ & 2.7 & 2.7 & 1.4 & Acceptable \\
\hline $\begin{array}{l}\text { Downstream Slope } \\
\text { Steady Seepage } \\
\text { at Top of Gate (elev }=750 \mathrm{ft} \text { ) }\end{array}$ & 2.7 & 2.7 & 1.5 & Acceptable \\
\hline $\begin{array}{l}\text { Downstream Slope } \\
\text { Normal Pool (elev }=744 \mathrm{ft}) \\
\text { Seismic 0.13g(H) }\end{array}$ & 1.8 & 1.8 & 1.0 & \\
\hline
\end{tabular}


TABLE 4 SUMMARY - SLOPE STABILITY ANALYSIS

SOIL PROFILE 3

\begin{tabular}{|l|c|c|c|c||}
\hline & \multicolumn{2}{|c|}{ MINIMUM FACTOR OF SAFETY } & \multirow{2}{*}{ COMMENTS } \\
\cline { 2 - 5 } LOADING CONDITIONS & $\begin{array}{c}\text { LOWER BOUND } \\
\text { PROPERTIES }\end{array}$ & $\begin{array}{c}\text { UPPER BOUND } \\
\text { PROPERTIES }\end{array}$ & FERC & \multirow{2}{*}{ Acceptable } \\
\hline $\begin{array}{l}\text { Upstream Slope } \\
\text { Rapid Drawdown } \\
\text { from Max Pool (elev = 755 ft) }\end{array}$ & 1.4 & 2.1 & 1.1 & \multirow{2}{*}{ Acceptable } \\
\hline $\begin{array}{l}\text { Upstream Slope } \\
\text { Rapid Drawdown } \\
\text { from Top of Gate (elev =750 ft) }\end{array}$ & 1.5 & 2.1 & 1.2 & Acceptable \\
\hline $\begin{array}{l}\text { Downstream Slope } \\
\text { Steady Seepage } \\
\text { at Max Pool (elev =755 ft) }\end{array}$ & 1.6 & 1.9 & 1.4 & Acceptable \\
\hline $\begin{array}{l}\text { Downstream Slope } \\
\text { Steady Seepage } \\
\text { at Top of Gate (elev }=750 \mathrm{ft})\end{array}$ & 1.7 & 1.9 & 1.5 & Acceptable \\
\hline $\begin{array}{l}\text { Downstream Slope } \\
\text { Normal Pool (elev }=744 \mathrm{ft}) \\
\text { Seismic 0.13g(H) }\end{array}$ & 1.0 & 1.4 & 1.0 & \\
\hline
\end{tabular}




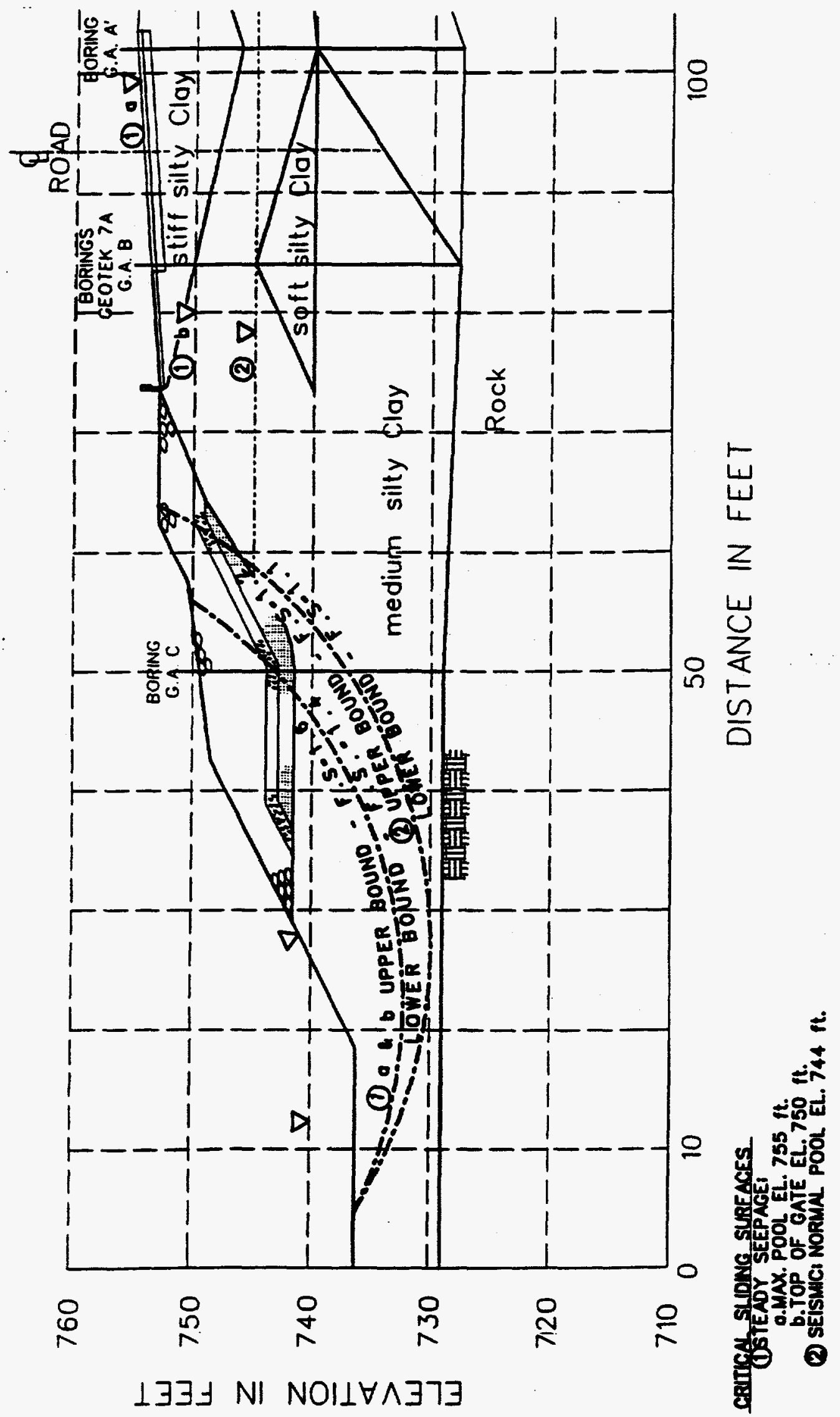

Figure 9 slope stability, soil Profile 1-1 critical sliding surfaces 


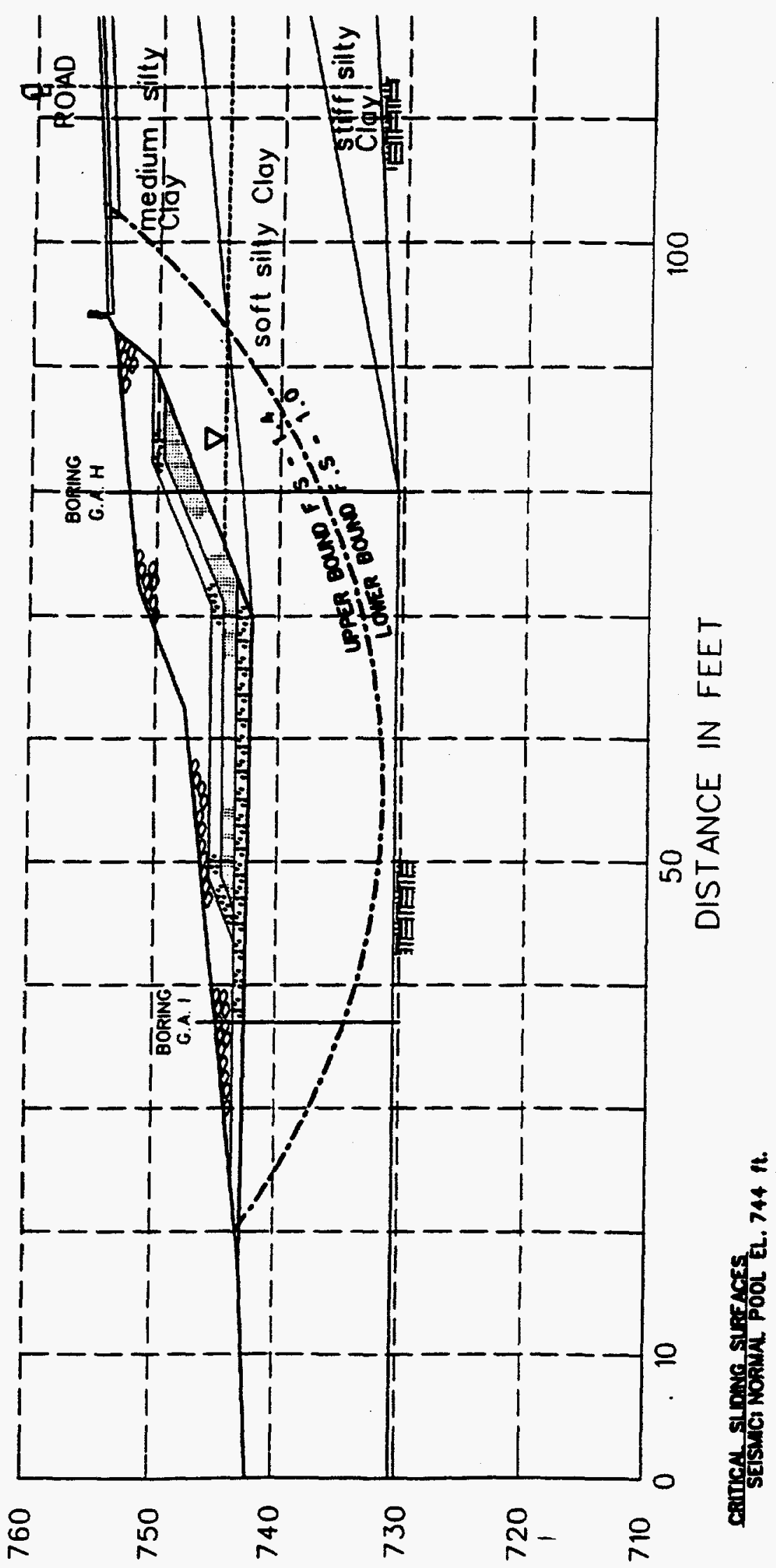

$\perp \exists \exists\lrcorner$ NI NOI $\forall \wedge \exists 7 \exists$

Figure 10 slope stability, Soil Profile 3-3 Critical sliding Surfaces 
profile 1 with steady seepage at Max. Pool, and the downstream slope at soil profile 3 with the Seismic loading, the minimum safety factors are equal to the FERC desired factors. For only one loading condition i.e., the downstream slope at soil profile 1 with steady seepage at top of gate, the lower bound properties yielded a safety factor $=1.4$ against FERC desired safety factor of 1.5 . For the same loading case, however, the upper bound properties resulted in a safety factor of 1.6. Therefore, it is interpreted that considering average properties, this loading condition also satisfies FERC desired safety factor.

The results of the analyses indicate that the White Oak Dam is safe and stable for the defined static and seismic loading conditions.

\subsection{LIQUEFACTION ASSESSMENT}

Liquefaction, or the loss of shear strength due to an increase in pore water pressure, is a phenomenon associated with saturated cohesionless soils. The increase in pore pressure is a result of the densification of loose soil, which may occur due to ground shaking. The increase in the pore pressure results in a decrease in the intergranular or effective stress, with a corresponding decrease in strength and stiffness. This densification can be a problem with coarse-grained cohesionless soils such as sands.

The cohesion and plasticity exhibited by fine-grained soils (silts and clays) restrict the tendency for volume decrease and pore pressure increase during ground shaking. Although recent research suggests that fine-grained soils may liquefy, liquefaction generally occurs only if the fines are totally non-plastic. Non-plastic fines occur in materials that are produced by the crushing of rock, such as, rock flour or man-made materials such as mine tailings. Even low plasticity silts formed by the weathering of rock have sufficient plasticity to restrict the densification upon shaking. Thus, it is the presence of plastic fines that prohibit the rearrangement of particles leading to densification and liquefaction.

The boring logs from the investigation of the White Oak Dam (Ref. 1 and 2) indicate that the embankment and foundation materials were classified as silts and clays. This means that the material is primarily fine-grained. All samples for which Atterberg limits were determined were found to have plastic limit. Based on the reported plasticity, these materials should not be susceptible to liquefaction.

The grain size distribution can provide a rough estimate of the susceptibility to liquefaction. Typical ranges for liquefiable soils are shown in Figure 11 (modified from the National Research Council 1985)(Ref. 18). This figure gives an indication of the grain size distribution range of sands for which liquefaction potential exists. The lower bound curve for potentially liquefiable soils suggests that if more than about 10 percent is finer than $0.01 \mathrm{~mm}$, the material will not liquefy.

The visual examination of all SPT samples, and the results of the Atterberg limits and natural moisture content determinations (Ref. 1 and 2) suggest that the WOD embankment and the foundation soils consist of silts and clays with substantial percentages of fine-grained material. These materials are expected to fall outside the lower range of potentially liquefiable soils. For comparison, a clayey silt (ML) and a silty clay (CL) from other location on the ORR (Ref. 19) are shown in Figure 11. These materials have similar Atterberg limits as the silty clays and clayey silts present at 


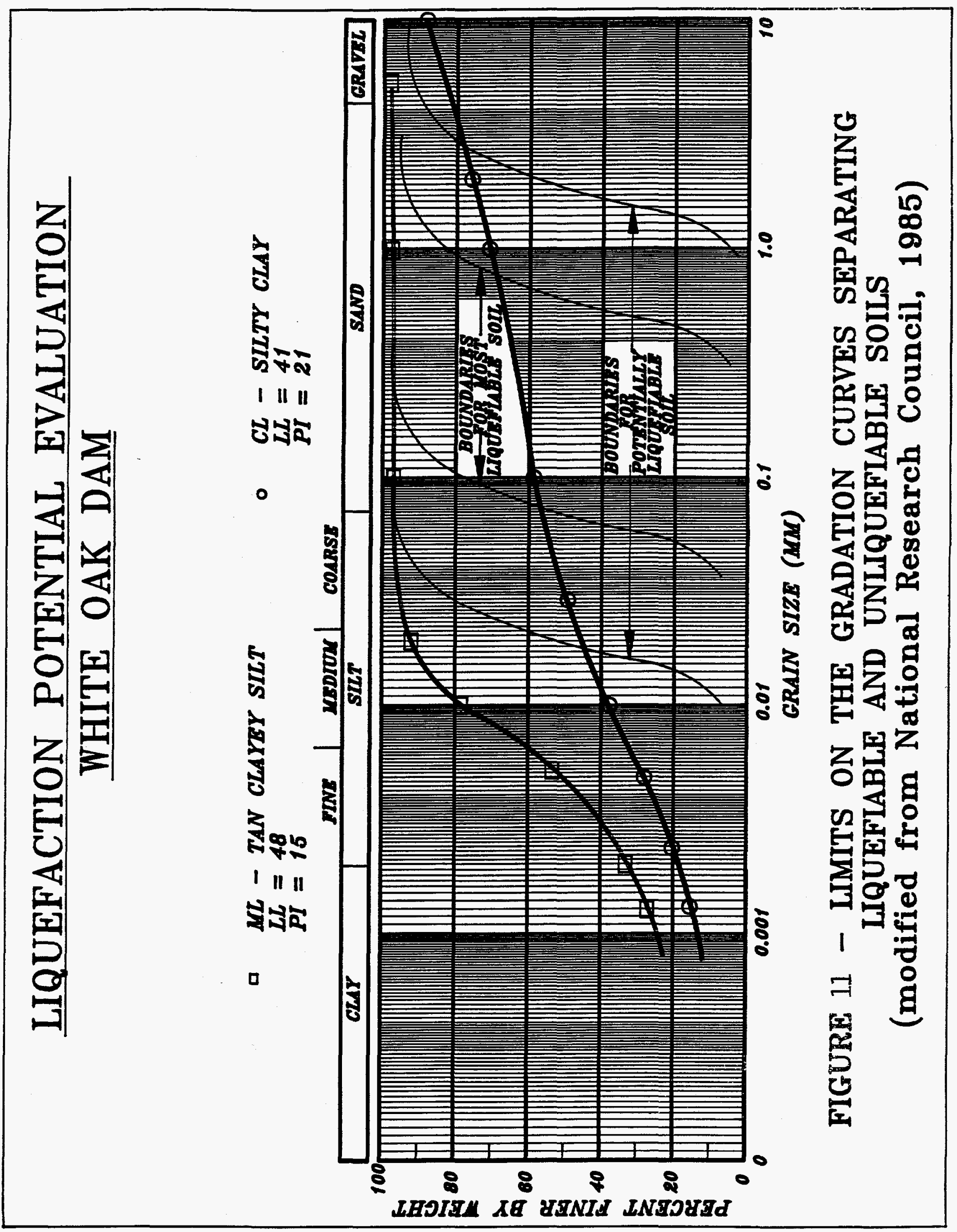


White Oak Dam. The significant amount of material that falls to the left of boundaries suggests minimal potential for liquefaction, due to the plastic fines. The coarse material found in the silty clay sample is due to the chert fragments suspended in the clay matrix. These dense chert fragments are found throughout the area, and tend to shift the grain-size distribution curve to the right, but will not affect the liquefaction potential.

To further demonstrate that the White Oak Dam embankment and foundation materials are not susceptible to liquefaction, a detailed evaluation of the potential for liquefaction has been performed. The evaluation is based upon Seed et al., methodologies for clayey soils and cohesionless soils with varying percentages of fines (Ref. 20). The liquefaction analysis presented is performed using the geotechnical information available in Ref. 1 and 2.

1. According to Seed et al., (Ref. 20) clayey soils may be vulnerable to liquefaction as a result of earth shaking if they have the following characteristics.

a) Percent finer than $.005 \mathrm{~mm}<15 \%$

b) Liquid Limit $<35$

c) Water Content $>.9 \times$ Liquid Limit

Additionally, "if soils with these characteristics plot above the A-Line on the Plasticity Chart, the best means of determining their cyclic loading characteristics is by tests. Otherwise, clayey soils may be considered nonvulnerable to liquefaction".

The data on liquid limit and natural water content reported in Ref. 1 and 2 are plotted on Fig. 12. It is clear from this plot that all twenty-five (25) samples are outside the zone of potential liquefaction. Fig. 13 shows the plots of the liquid limits and plasticity indices on the Plasticity Chart. The plot indicates that twenty-three (23) points are below the A-line and therefore they are not liquefiable. The remaining two (2) points which are just above the A-line are plotted in the nonliquefiable zone on Fig. 12.

Grain size analyses were performed on twelve (12) samples by GEOTEK (Ref. 1). The test results indicate the percentage of soil particles finer than $.005 \mathrm{~mm}$ varies from 3 to 22 percent. Although some samples do not satisfy Seed et al., criteria for the percent finer than $.005 \mathrm{~mm}$, the amount of percent finer than 200 sieve (defined as 'fines') is in the range of 27 to 53 which suggest that the samples have sufficient fines to prevent liquefaction.

Grain size distribution data are not available in Ref. 2, however, it is interpreted from the visual soil classification, natural moisture content, and Atterberg limits that the White Oak Dam embankment and foundation soils should have sufficient fines to qualify as nonliquifiable soils.

2. Seed et al, have developed the boundaries of liquefaction zones for sandy soils containing varying percentages of fines (Ref. 20 and 21). These boundaries are based upon the relationship between the SPT blow counts (N) and the Cyclic Stress Ratio (CSR).

All SPT samples from Ref. 1 and 2 are evaluated for liquefaction potential using $\mathrm{N}$ values and the corresponding CSRs. The $\mathrm{N}$ values are corrected for overburden, hammer energy ratio, and very short drill rod lengths. Overburden correction is applied using the method recommended by Liao and 


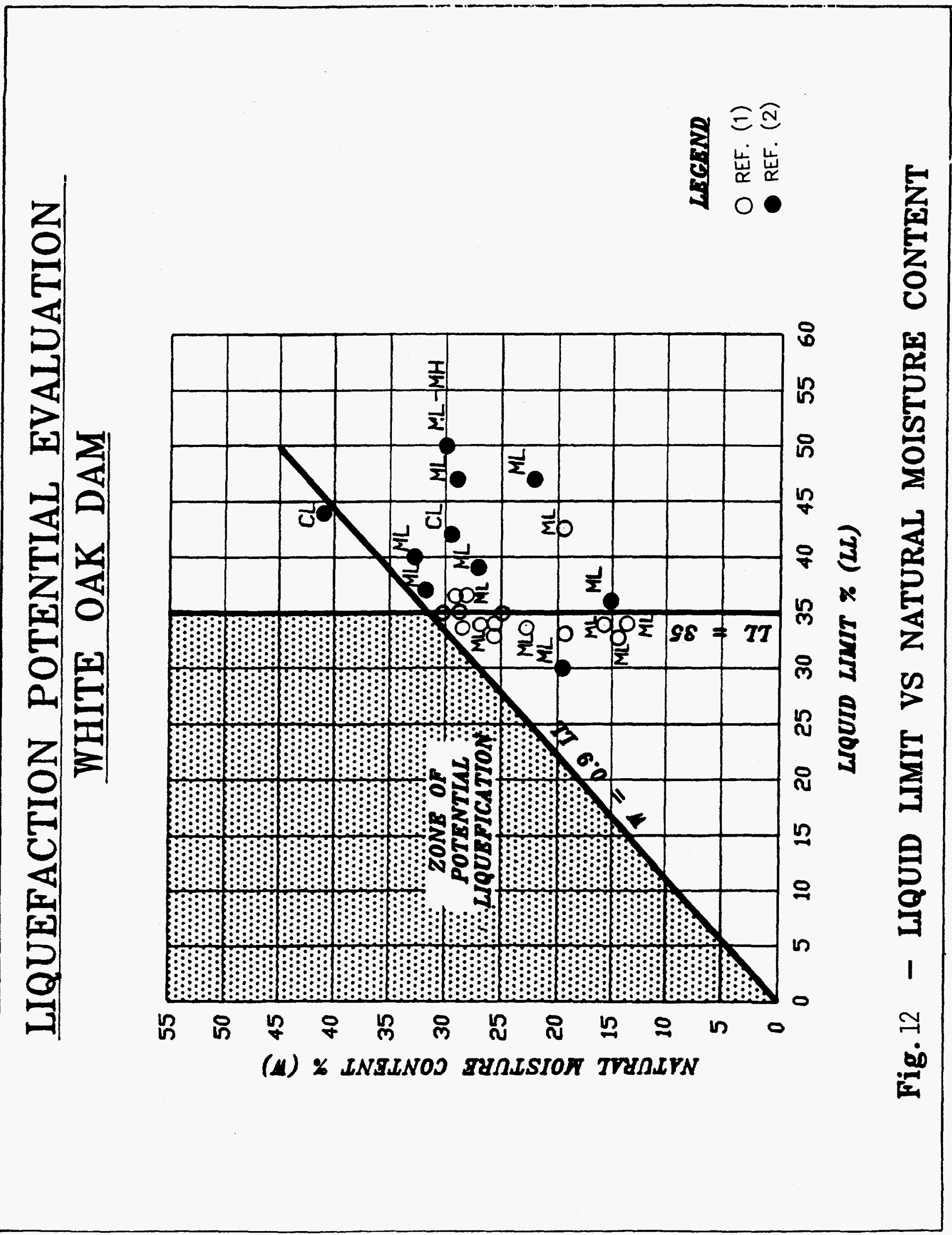



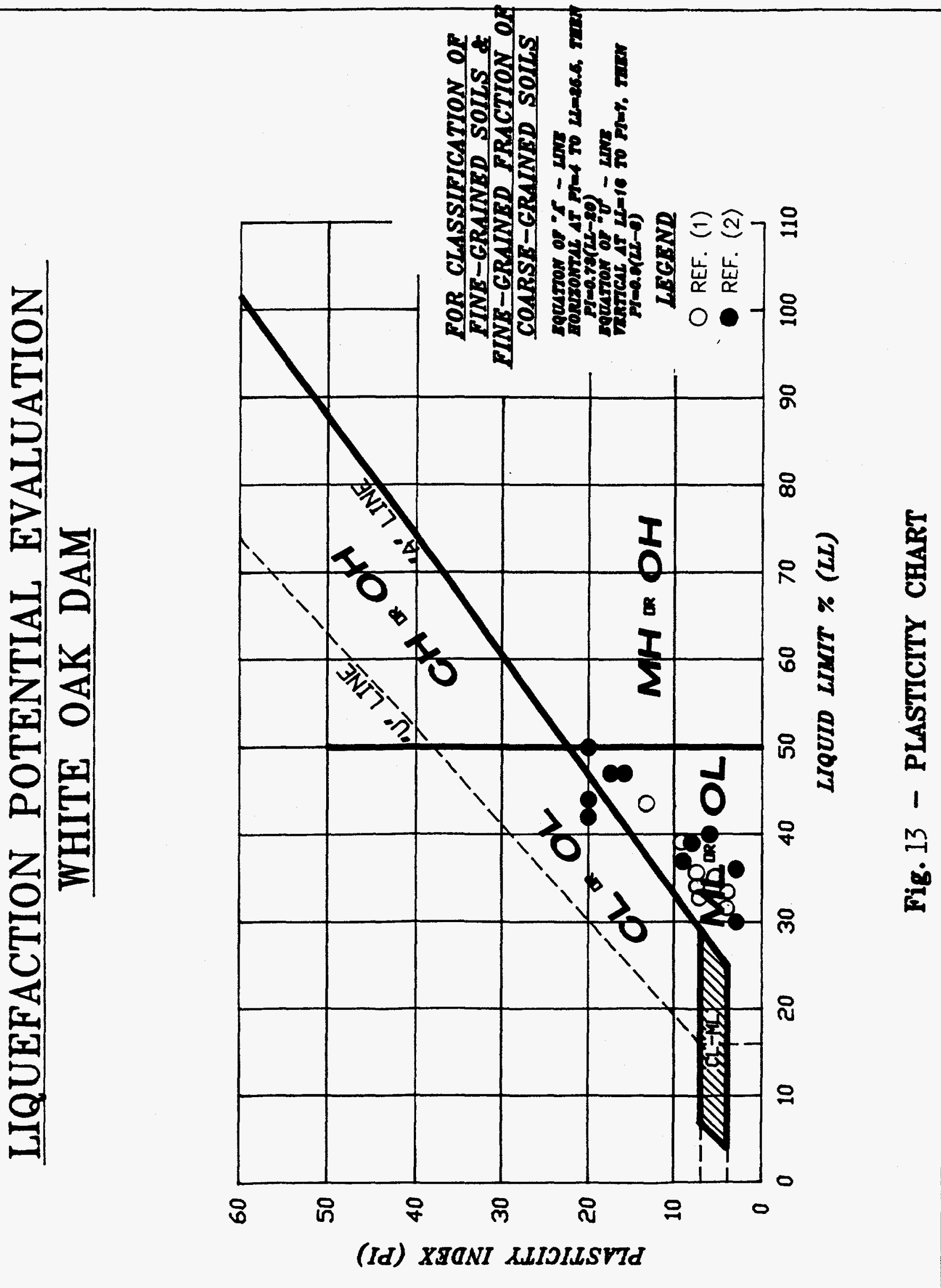
Whitman (Ref. 22). For hammer energy ratio, a correction factor of 1.0 has been used assuming a standard energy ratio of 60 percent of the free fall energy of the hammer (Ref. 21). To account for very short drill lengths, a correction factor of 0.75 is applied for sampling depths less than 10 feet (Ref. 21).

The corrected $\mathrm{N}$ values are designated by the symbol $\left(\mathrm{N}_{1}\right)_{60}$ on Figures 14 to 23 . The CRS is computed from the following equation:

$$
\frac{\tau_{\text {ave }}}{\sigma^{1}} \approx 0.65\left(\frac{a_{\max }}{g}\right)\left(\frac{\sigma}{\sigma^{1}}\right)\left(r_{d}\right)
$$

$\tau_{\text {ave }}=$ Average Cyclic Shear Stress

$\sigma=$ Vertical total Stress

$\sigma^{1}=$ Vertical Effective Stress

$\mathrm{a}_{\max }=$ Maximum ground Acceleration

$\mathrm{g}=$ Acceleration Due to Gravity

$r_{d}=$ Stress reduction factor

Stress reduction factors are taken from Ref. (23). Groundwater elevations observed in the borings in Ref. 1 and 2 are used to determine the vertical effective stresses.

Three curves were developed by Seed et al., to evaluate liquefaction potential for silty sands containing $<5 \%, 15 \%$, and 35\% fines for a Richter earthquake magnitude of 7.5 (Ref. 21). The magnitude of the Evaluation Basis Earthquake at the White Oak Dam was determined to be on the order of 5.6. Therefore, a correction factor $=1.4$ has been applied to the three curves.

Corrected blow counts and the corresponding CSRs are calculated and presented in Appendix A-3. Plots of the corrected blow counts and the CSRs for samples in each boring are shown on Fig. 14 through 28 . It is obvious from these plots that a majority of the data points are below the curve for $5 \%$ fines, indicating that they are not vulnerable to liquefaction. There are, however, some points located between the curves for 5\% and $15 \%$ fines and very few points between the curves for $15 \%$ and $35 \%$ fines. The visual soil classification with detail description for all samples, and natural moisture contents and Atterberg limits on the 25 representative samples, indicate that the soils are not sandy types and should contain sufficient fines, and therefore, the possibility of liquefaction can be ruled out. 


\section{LIQUEFACTION POTENTIAL EVALUATION WHITE OAK DAM}

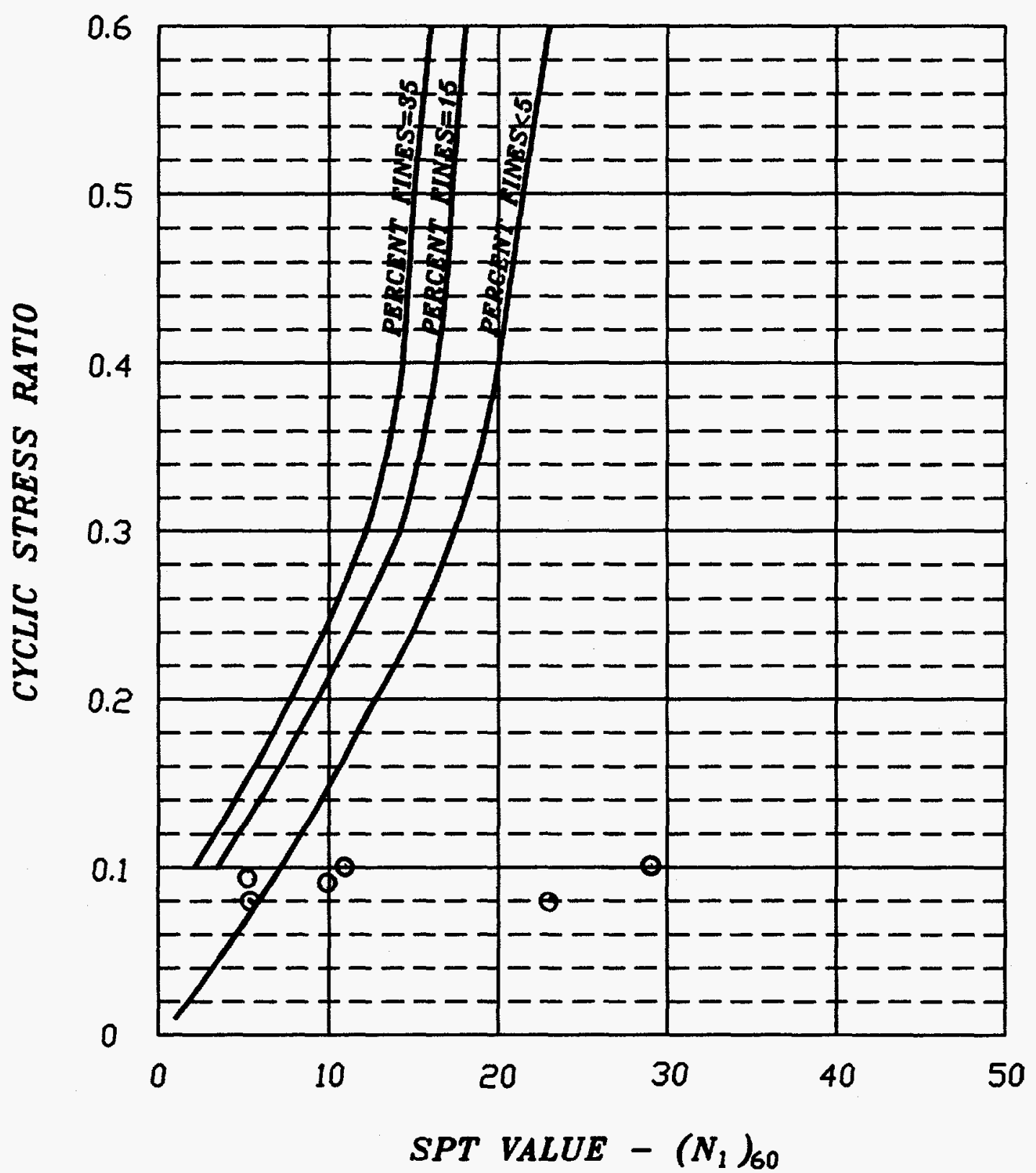

LEGEND:

SPT SAMPLE O BORING $A^{\prime}$

Fig. 14 - NO OF BLOWS VS CYCLIC STRESS RATIO 


\section{LIQUEFACTION POTENTIAL EVALUATION WHITE OAK DAM}

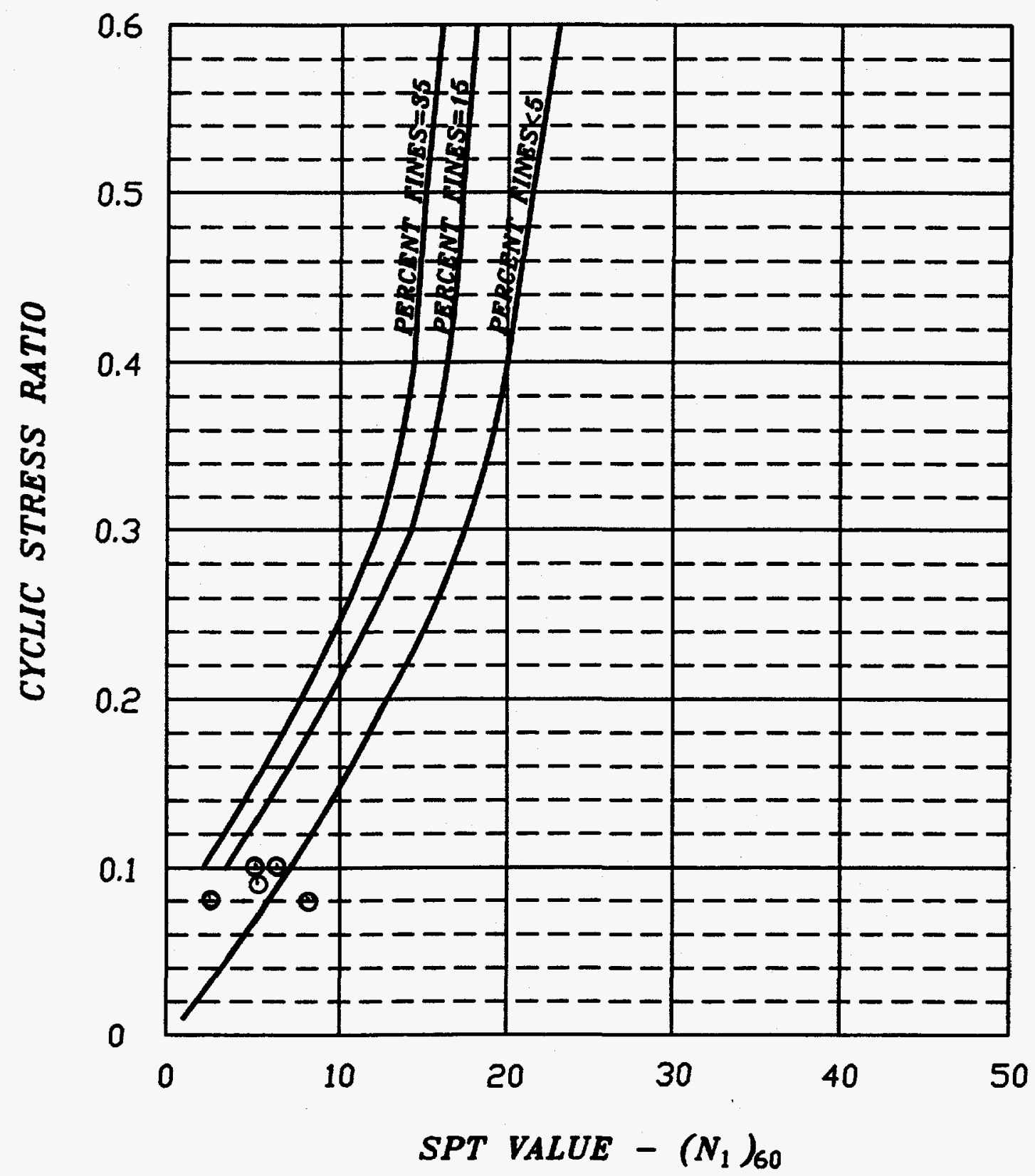

LEGEND: SPT SAMPLE O BORING B 
LIQUEFACTION POTENTIAL EVALUATION WHITE OAK DAM

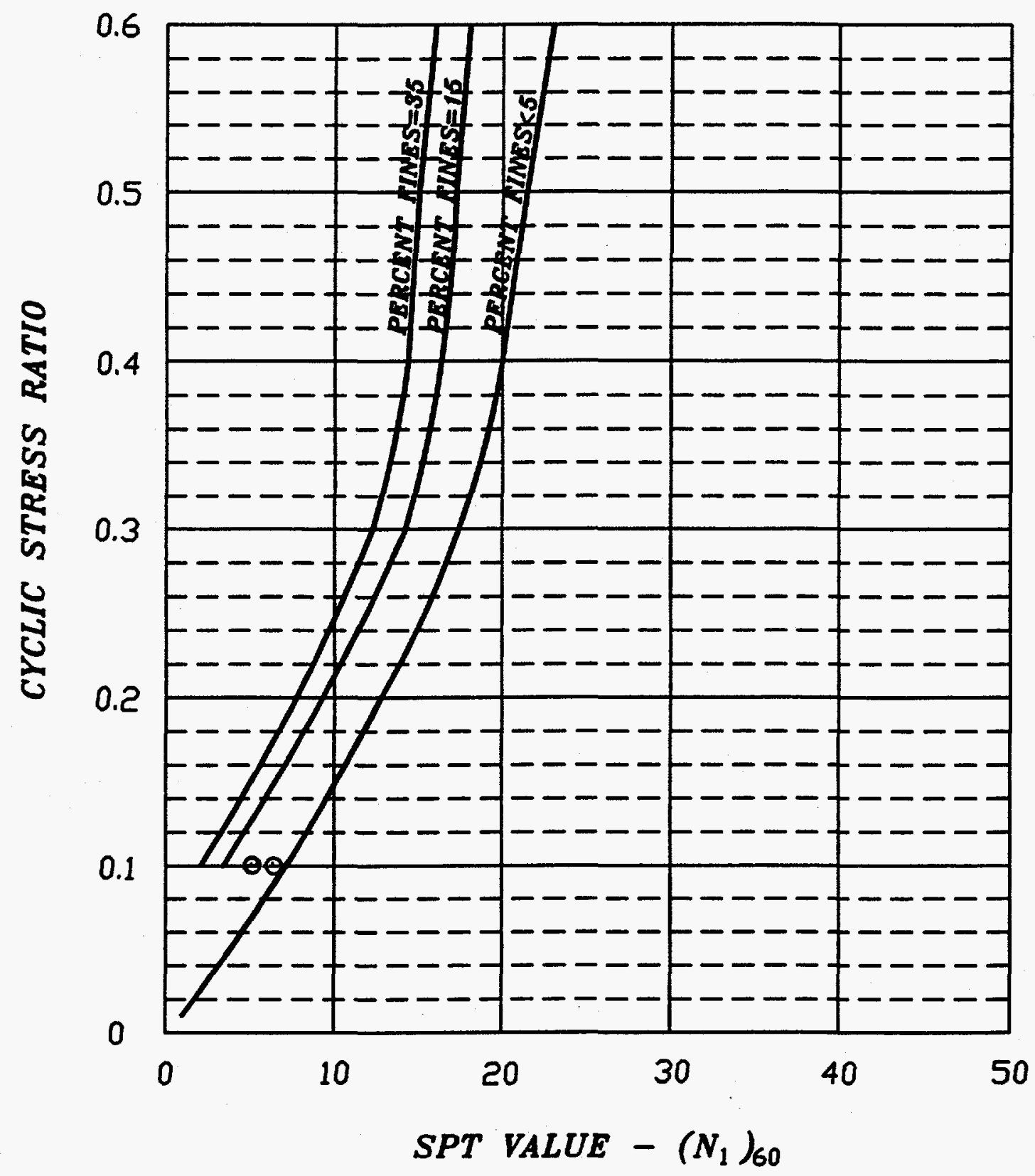

LEGEND: SPT SAMPLE 0 BORING $C$

Fig. 16 - NO OF BLOWS VS CYCLIC STRESS RATIO 


\section{LIQUEFACTION POTENTIAL EVALUATION WHITE OAK DAM}

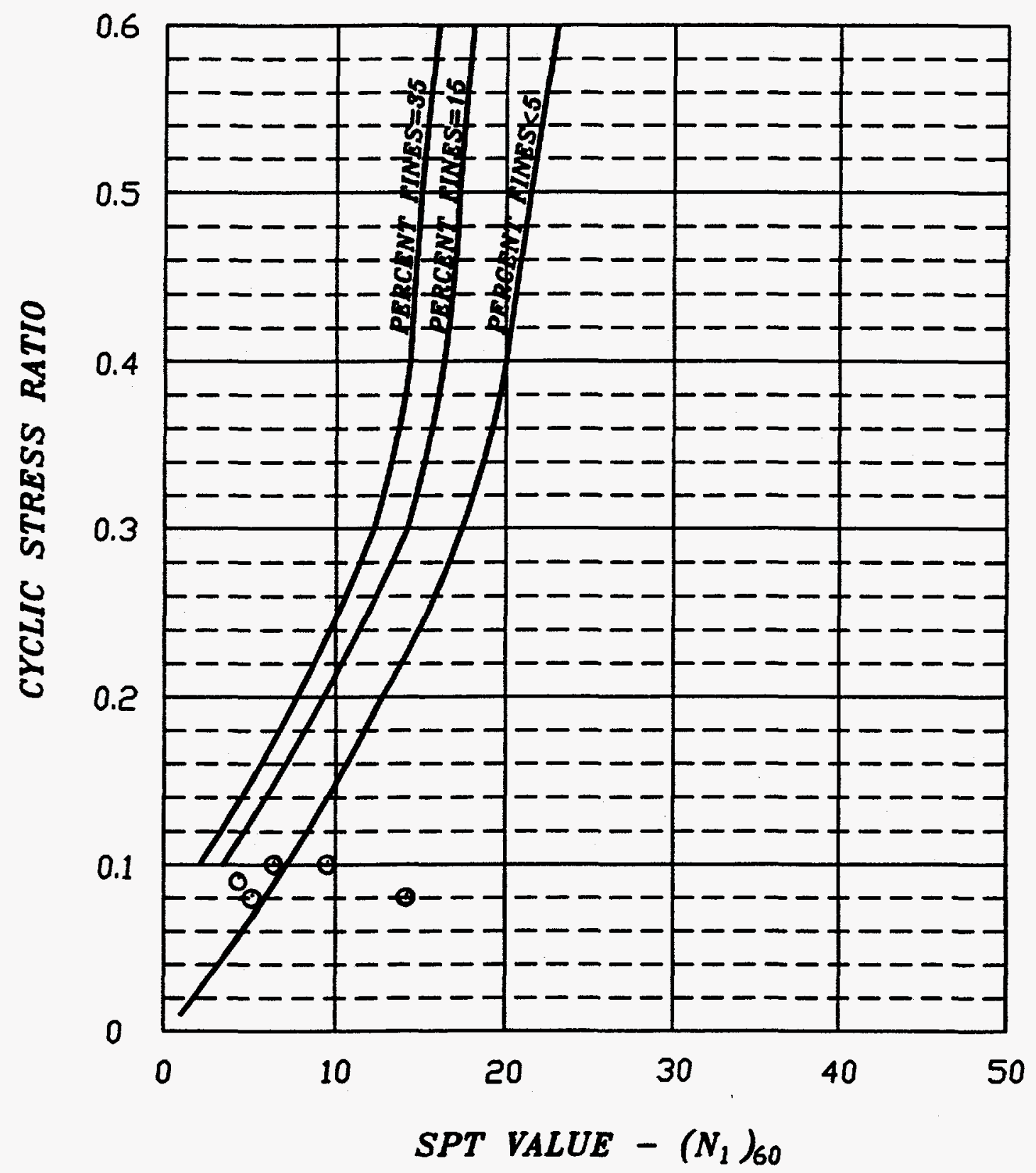

LEGEND: SPT SAMPLE O BORING $D^{\prime}$

Fig. 17 - NO OF BLOWS VS CYCLIC STRESS RATIO 


\section{LIQUEFACTION POTENTIAL EVALUATION WHITE OAK DAM}

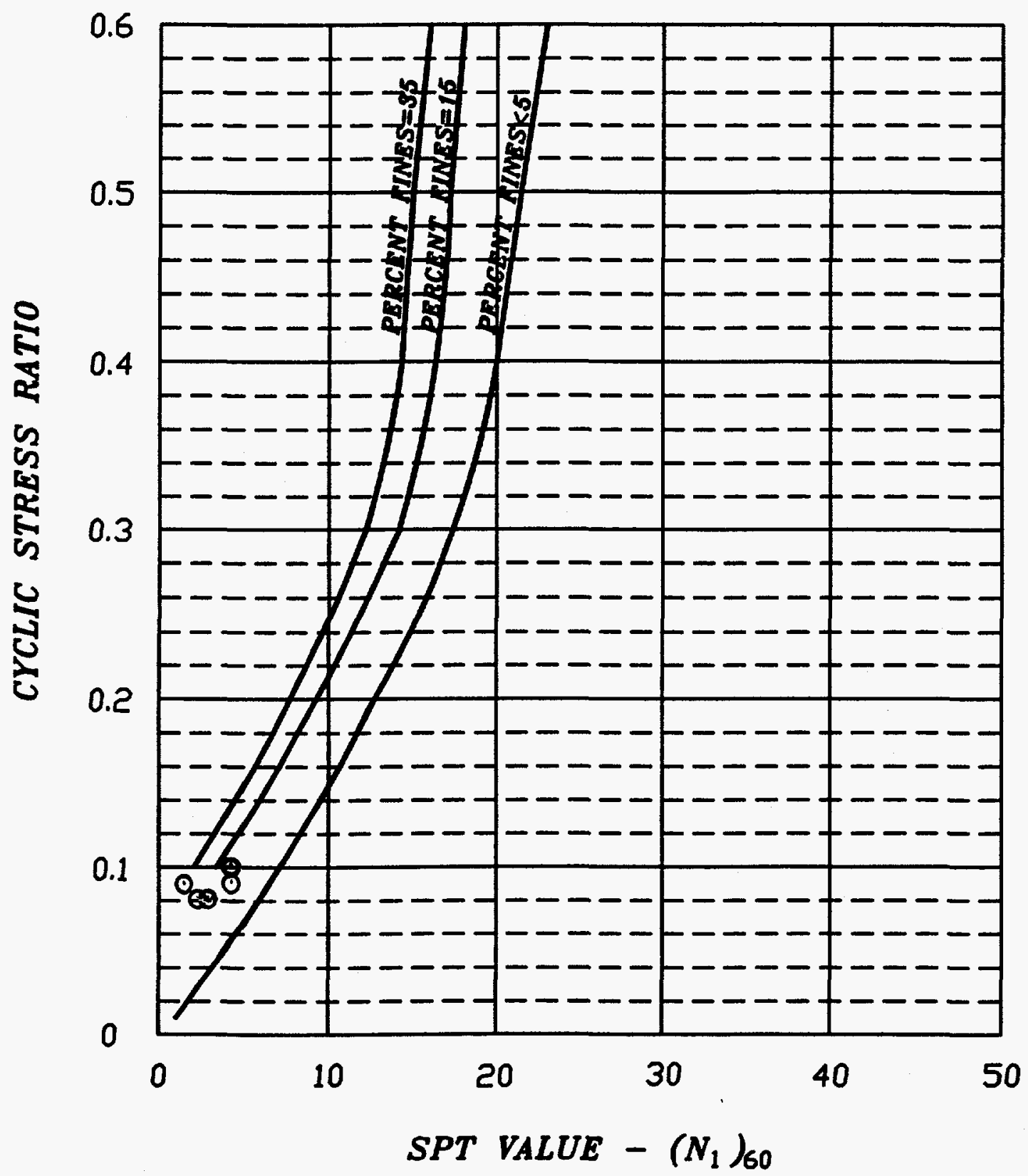

LEGEND: $S P T$ SAMPLE 0 BORING E

Fig. 18 - NO OF BLOWS VS CYCLIC STRESS RATIO 


\section{LIQUEFACTION POTENTIAL EVALUATION WHITE OAK DAM}

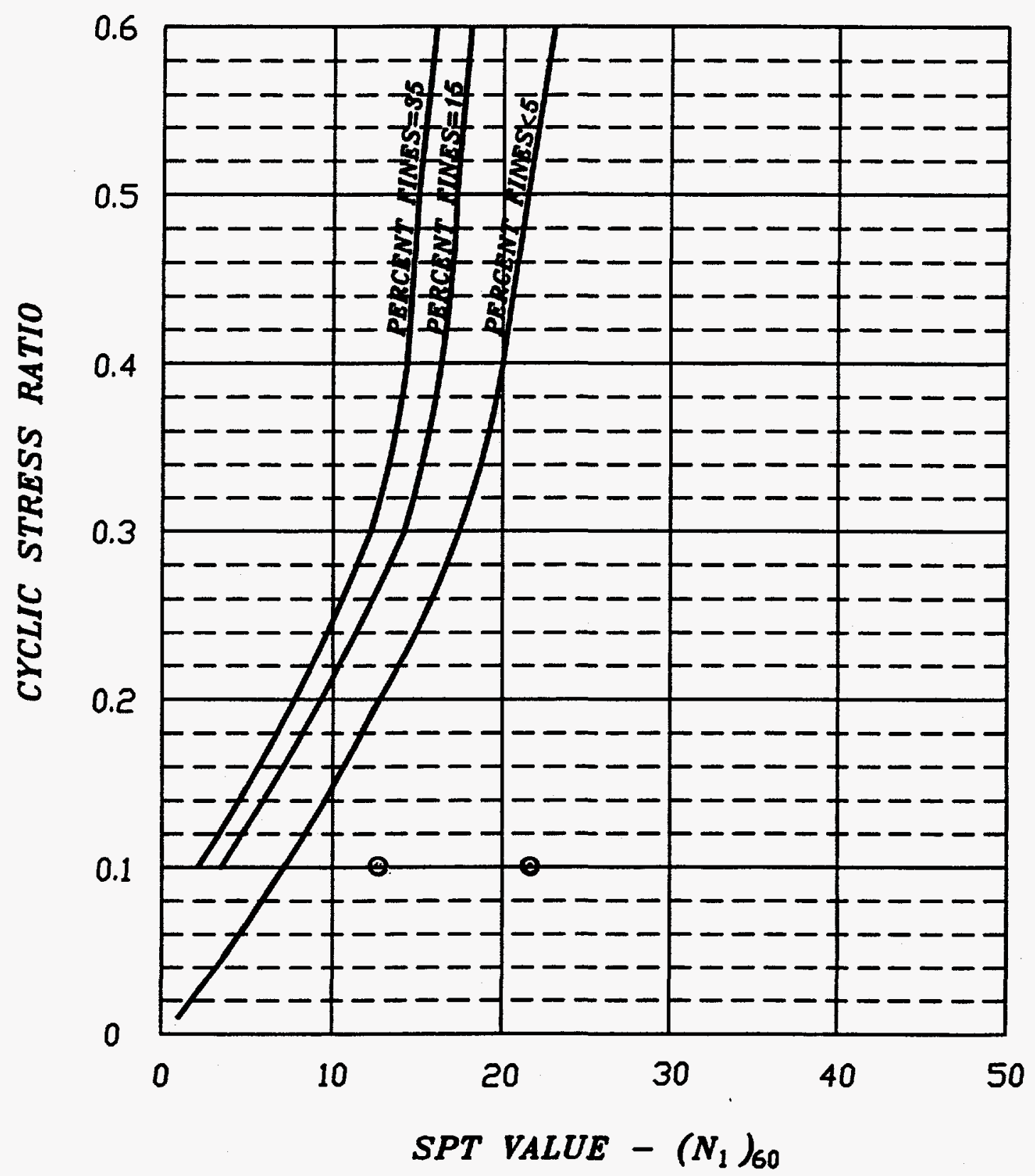

LEGEND:

$S P T$ SAMPLE 0 BORING F

Fig. 19 - NO OF BLOWS VS CYCLIC STRESS RATIO 


\section{LIQUEFACTION POTENTIAL EVALUATION WHITE OAK DAM}

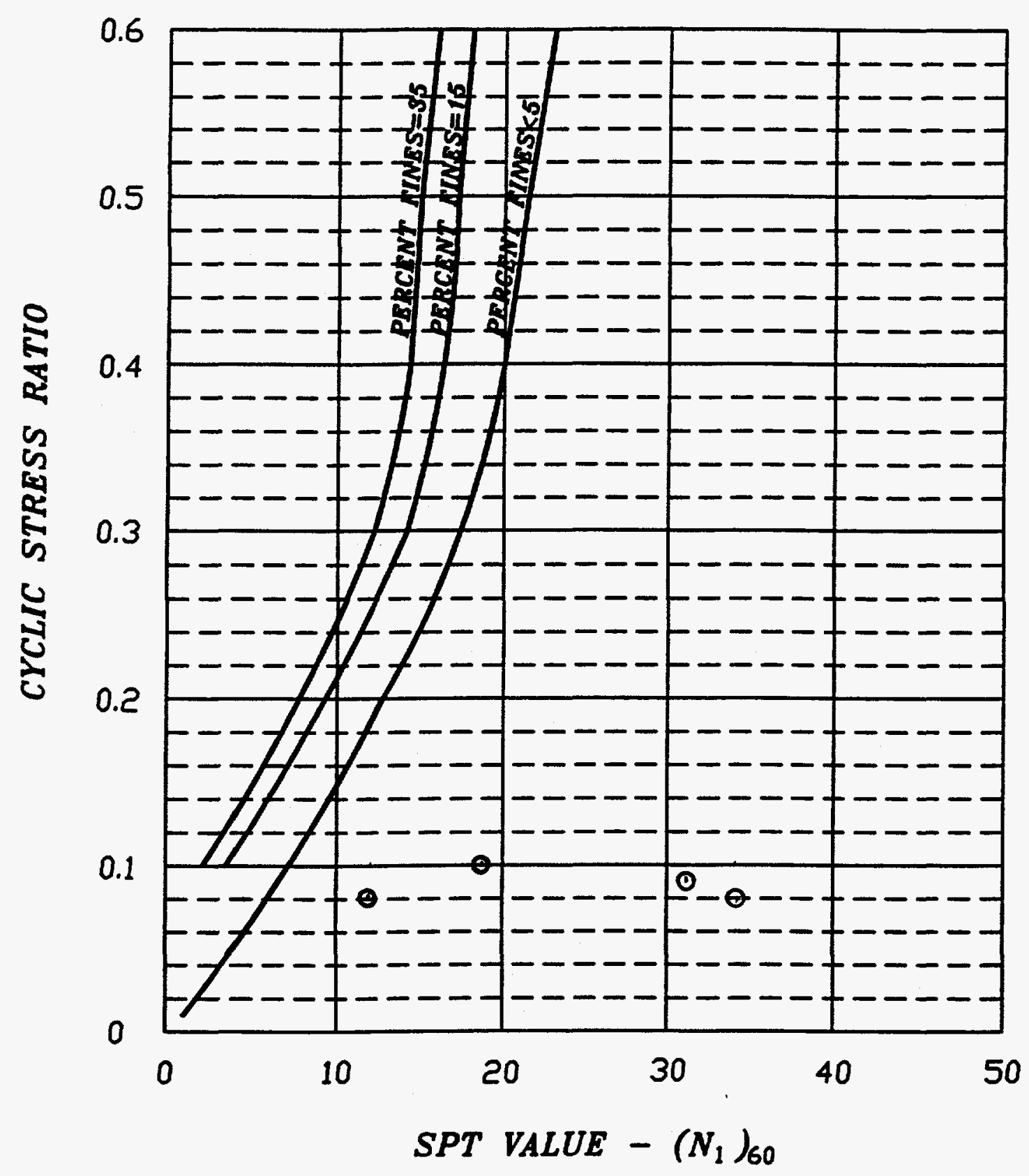

o

LEGEND:

SPT SAMPLE O BORING $G^{\prime}$

Fig. 20 - NO OF BLOWS VS CYCLIC STRESS RATIO 


\section{LIQUEFACTION POTENTIAL EVALUATION WHITE OAK DAM}

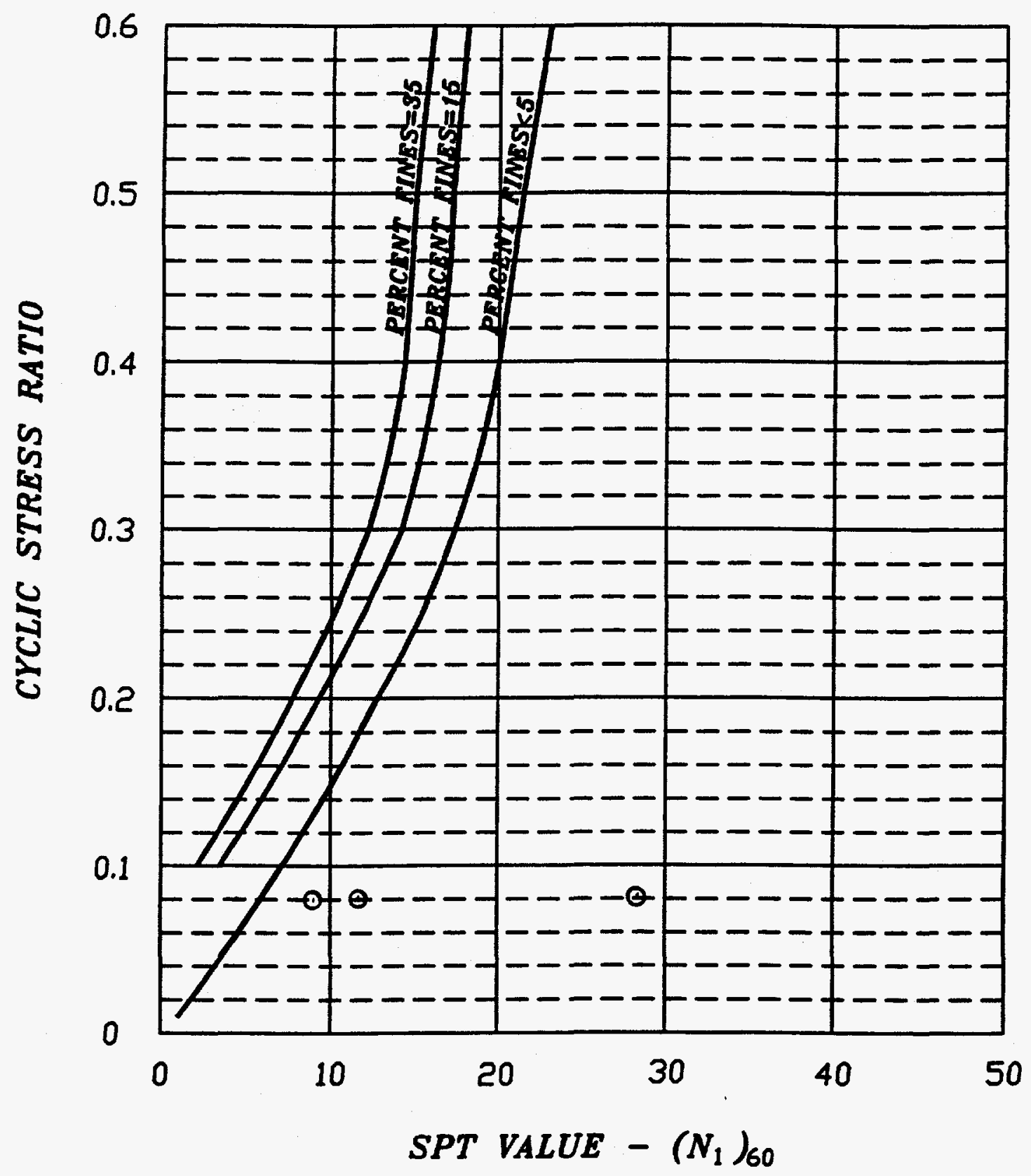

LEGEND: $S P T$ SAMPLE 0 BORING H'

Fig. 21 - NO OF BLOWS VS CYCLIC STRESS RATIO 


\section{LIQUEFACTION POTENTIAL EVALUATION WHITE OAK DAM}

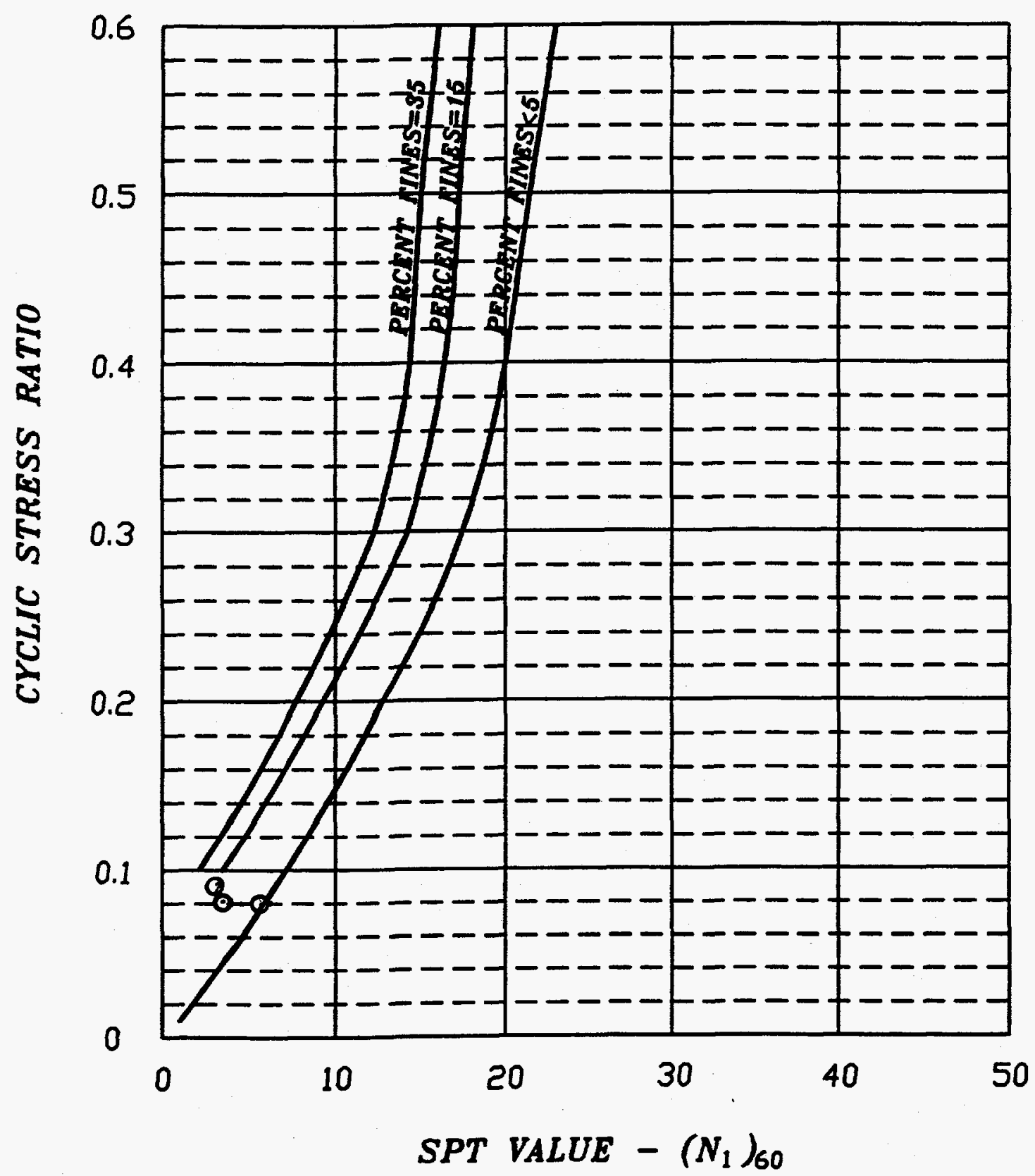

LEGEND:

SPT SAMPLE O BORING H

Fig. 22 - NO OF BLOWS VS CYCLIC STRESS RATIO 


\section{LIQUEFACTION POTENTIAL EVALUATION WHITE OAK DAM}

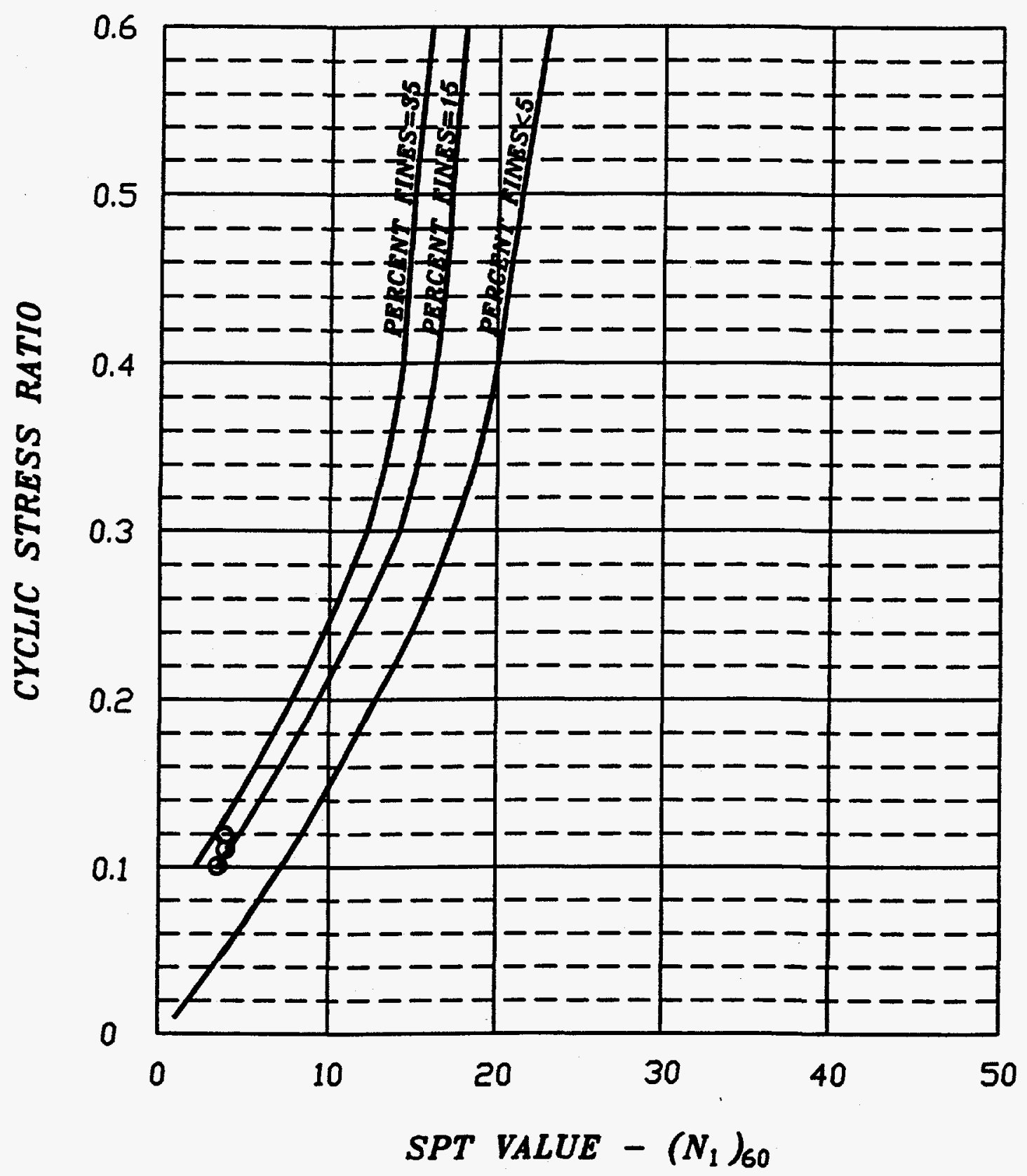

LEGEND:

SPT SAMPLE 0 BORING I

Fig. 23 - NO OF BLOWS VS CYCLIC STRESS RATIO 


\section{LIQUEFACTION POTENTIAL EVALUATION WHITE OAK DAM}

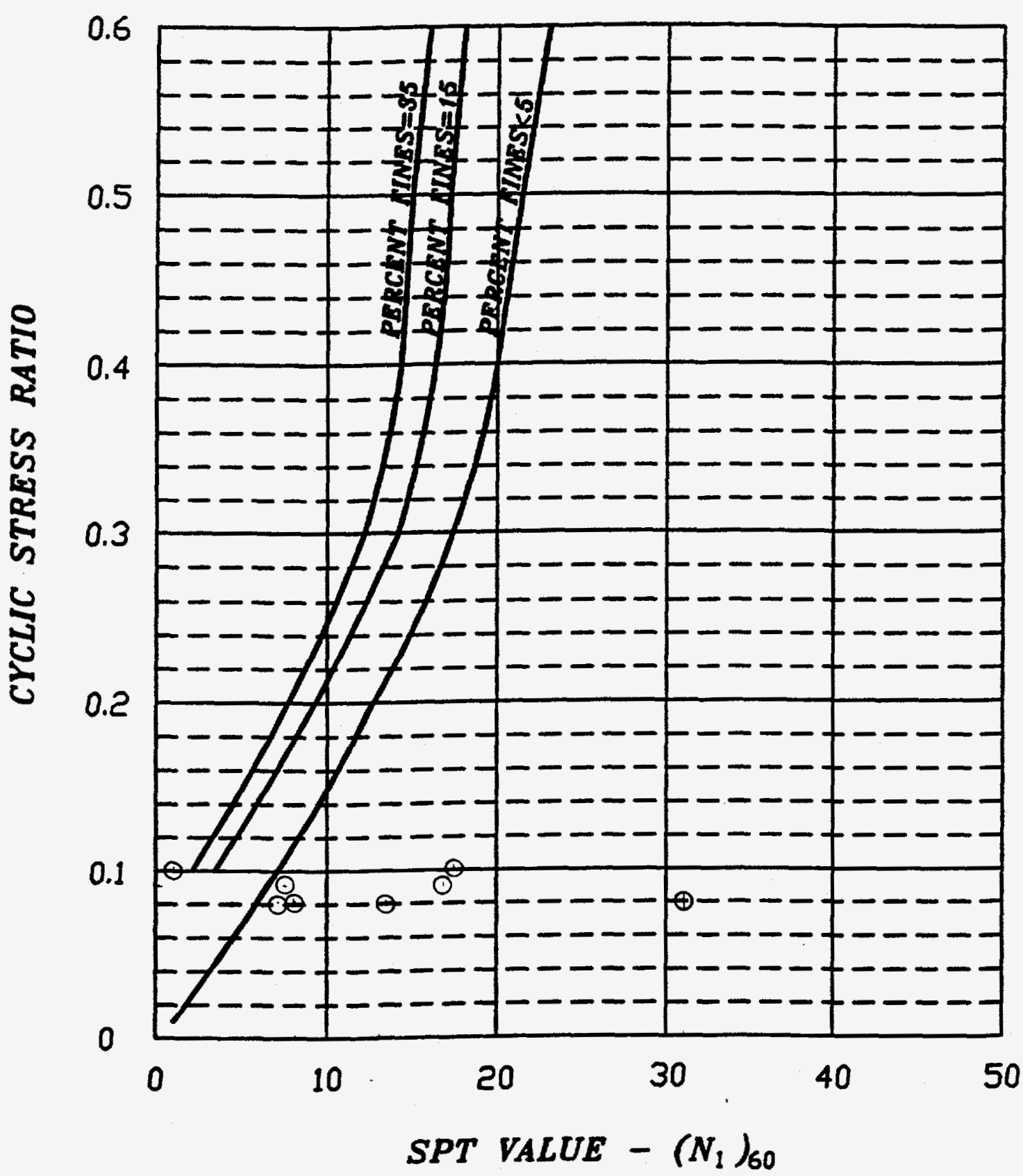

LEGEND: SPT SAMPLE BORING 4 


\section{LIQUEFACTION POTENTIAL EVALUATION WHITE OAK DAM}

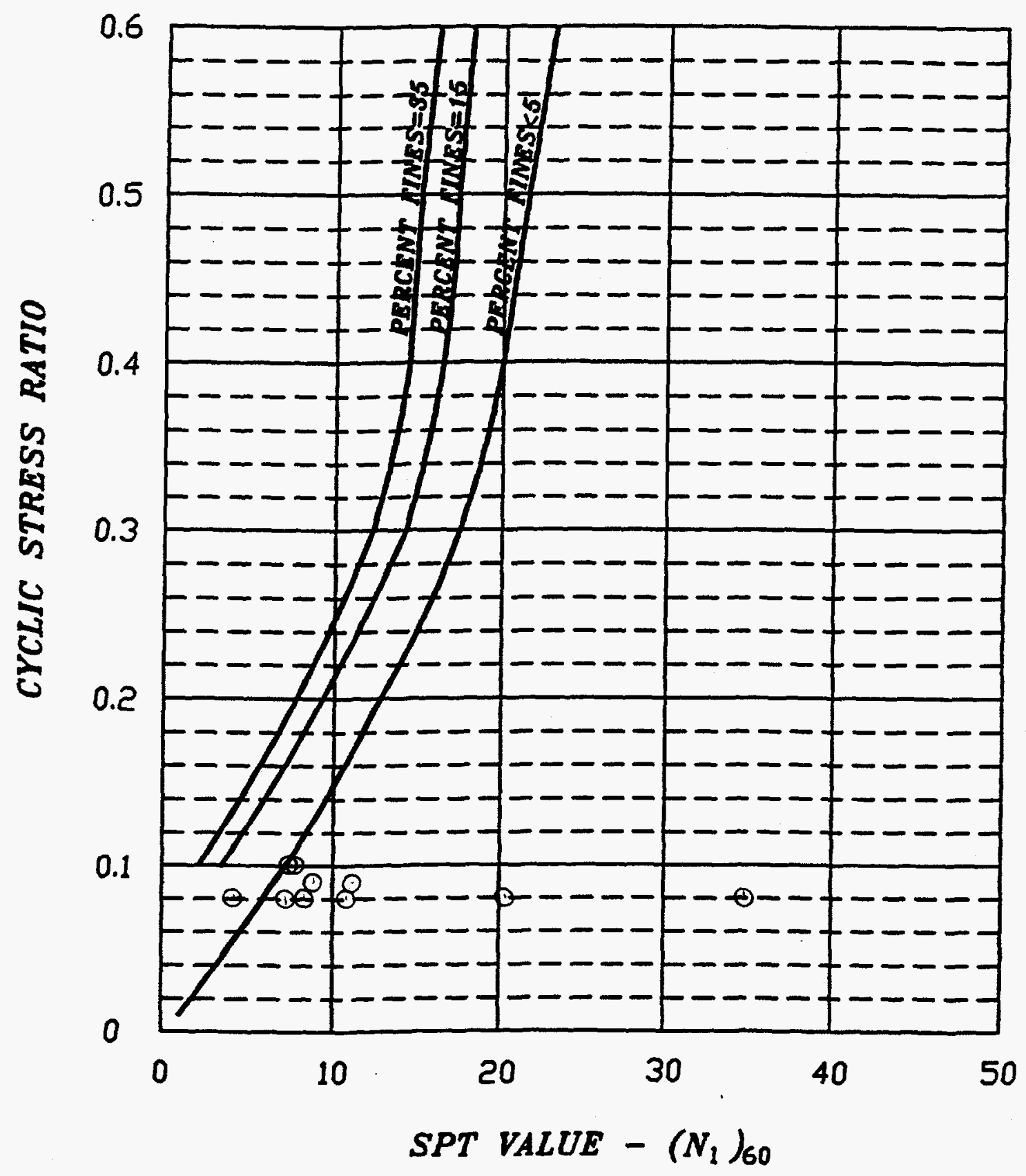

LEGEND: SPT SAMPLE BORING 5

Fig. 25 - NO OF BLOWS VS CYCLIC STRESS RATIO 


\section{LIQUEFACTION POTENTIAL EVALUATION WHITE OAK DAM}

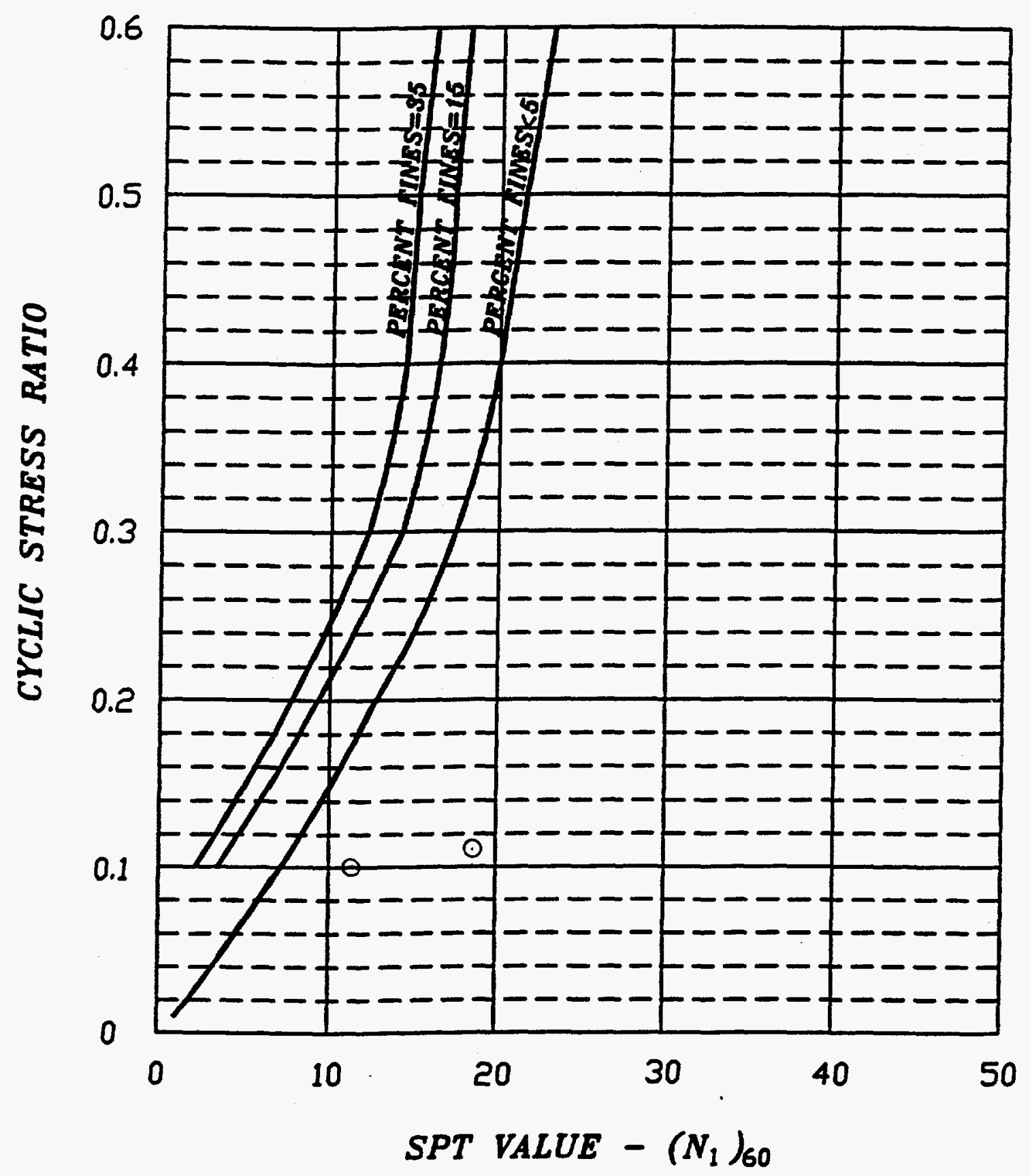

LEGEND: SPT SAMPLE BORING 6 


\section{LIQUEFACTION POTENTIAL EVALUATION}

\section{WHITE OAK DAM}

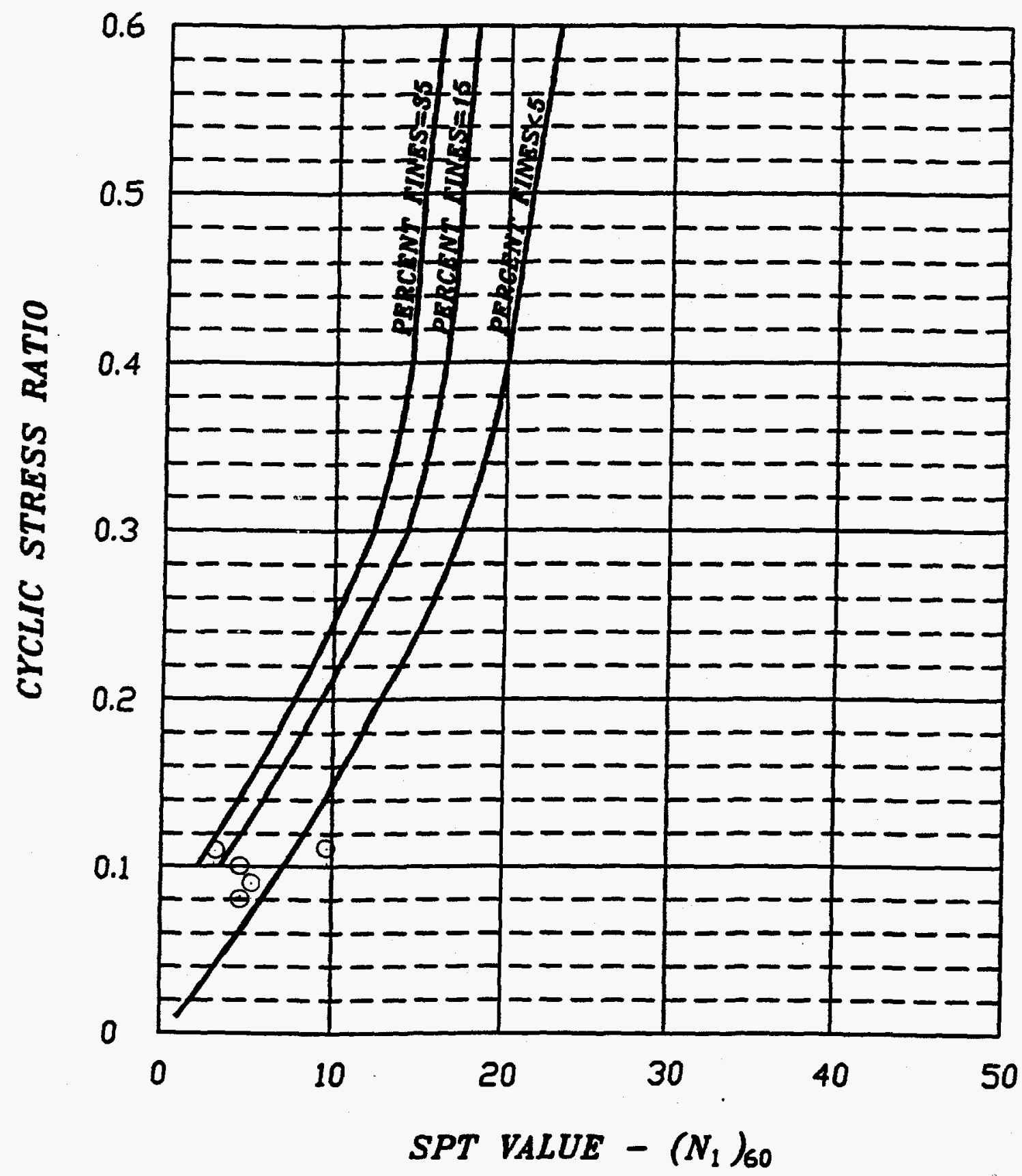

LEGEND :

SPT SAMPLE

BORING $7 B$

Ei 27 - NO NF RINWS VS CYCLIC STRESS RATIO 


\section{LIQUEFACTION POTENTIAL EVALUATION WHITE OAK DAM}

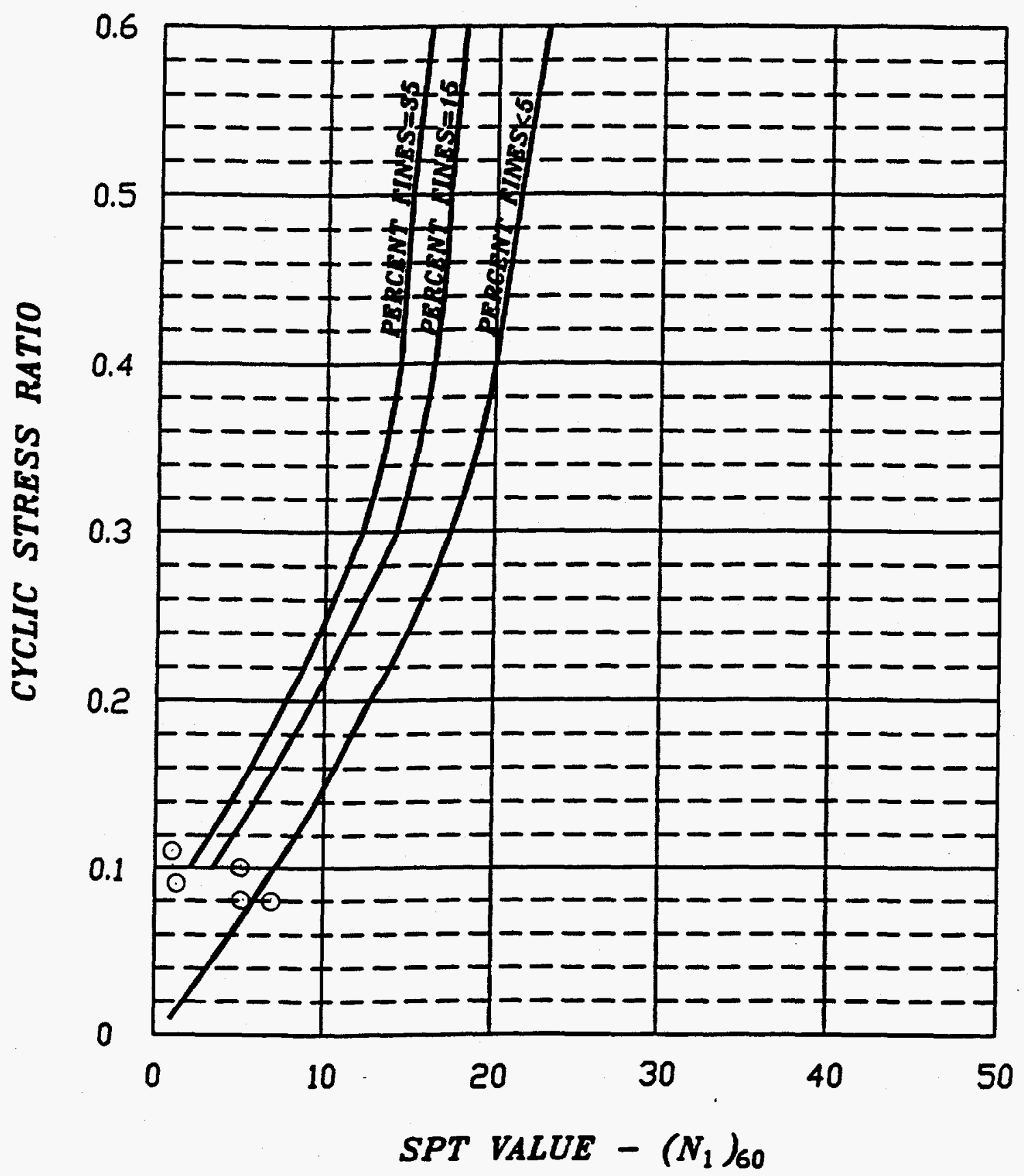

LEGEND: SPT SAMPLE BORING 8 
Based upon the results of the foregoing liquefaction analysis, it is concluded that the White Oak Dam embankment and the foundation soils are not vulnerable to liquefaction.

\subsection{INSPECTION AND MAINTENANCE}

A management action plan has been prepared (Ref. 28) in order to provide operation and maintenance, periodic inspection, and emergency action plans for White Oak Dam in general accordance with the Federal Emergency Management Agency (FEMA) guidelines for dam safety. This management action plan has been implemented since January 1989 .

The periodic inspection program covers the features of the dam and its associated structures and equipment to be inspected, frequency of inspections, types of inspections, inspection schedule, and description of required repairs.

The Emergency Action Plan is maintained to prevent failure or to minimize the effects of failure of the dam. Actions to be taken upon discovery of a potential problem have been outlined. The plan is in accordance with DOE orders and includes notification, warning, and response actions.

\subsection{PERIODIC INSPECTION PROGRAM}

The periodic inspection program consists of a) Informal, b) Intermediate, c) Formal, and d) Special inspections.

a. Informal Inspections are made monthly at the White Oak Dam site under normal operating conditions, but weekly checks are implemented if the lake elevation rises to $749 \mathrm{ft}$. or above. The weekly checks are continued for four weeks after the lake elevation returns to approx. elevation 745 $\mathrm{ft}$. These informal inspections are made by a team composed of MMES Engineering and from Environmental Monitoring and Compliance (EMC). A detailed check list has been prepared which includes the detection of seepage, piping, slope instability, settlement, cracking, and tilting.

b. Intermediate inspections are made on an annual basis. MMES Engineering is in charge of the inspection team which is composed of engineers, geologists and EMC personnel. This inspection includes a thorough field inspection and a review of inspection records from and following the last formal inspection.

Under the agreement formalized between DOE and FERC, an annual inspection is performed by a FERC inspector and the inspection reports are prepared and forwarded to the concerned agencies.

c. Formal inspections are made every five years and MMES Engineering oversees the inspection team. The formal inspection is directed by a licensed professional engineer and includes site inspection, review of informal, intermediate, and formal inspection documents and a review to determine whether White Oak Dam meets the current accepted standards and practices.

Ogden Environmental and Energy Services have performed the formal inspection (5-year inspection) on November 16, 1993, and submitted the inspection report (Ref. 29). Representatives from MMES, DOE, and Tennessee Department of Energy and Conservation (TDEC) were present during the site inspection. No unusual conditions or potential problems that would adversely affect 
the structural integrity of the White Oak Dam were observed during this inspection. However, some maintenance-type items have been addressed in the inspection report. Based upon the review of the i) Previous reports of informal and intermediate inspections performed by MMES, ii) Annual inspection reports by FERC, iii) Quarterly monument survey data obtained by MMES, and iv) Ref. 15 and 30, Ogden believes that White Oak Dam is in compliance with the regulatory requirements of the FEMA, FERC, and the State of Tennessee Safe Dams Program.

d. Special inspections will be made after the dam has been overtopped, if slope failure of the face of the dam occurs, or after any seismic event. MMES will oversee the special inspection team which will be directed by a licensed professional engineer.

Additionally, nine control monuments have been installed on the crest and the slopes of the White Oak Dam to monitor the lateral and vertical movements of the embankment. The locations of the control monuments are shown on Fig. 29. These monuments are surveyed on a quarterly basis by MMES survey crew.

The effectiveness of the Management Plan for White Oak Dam is tested by conducting the Emergency Drill on an annual basis. 


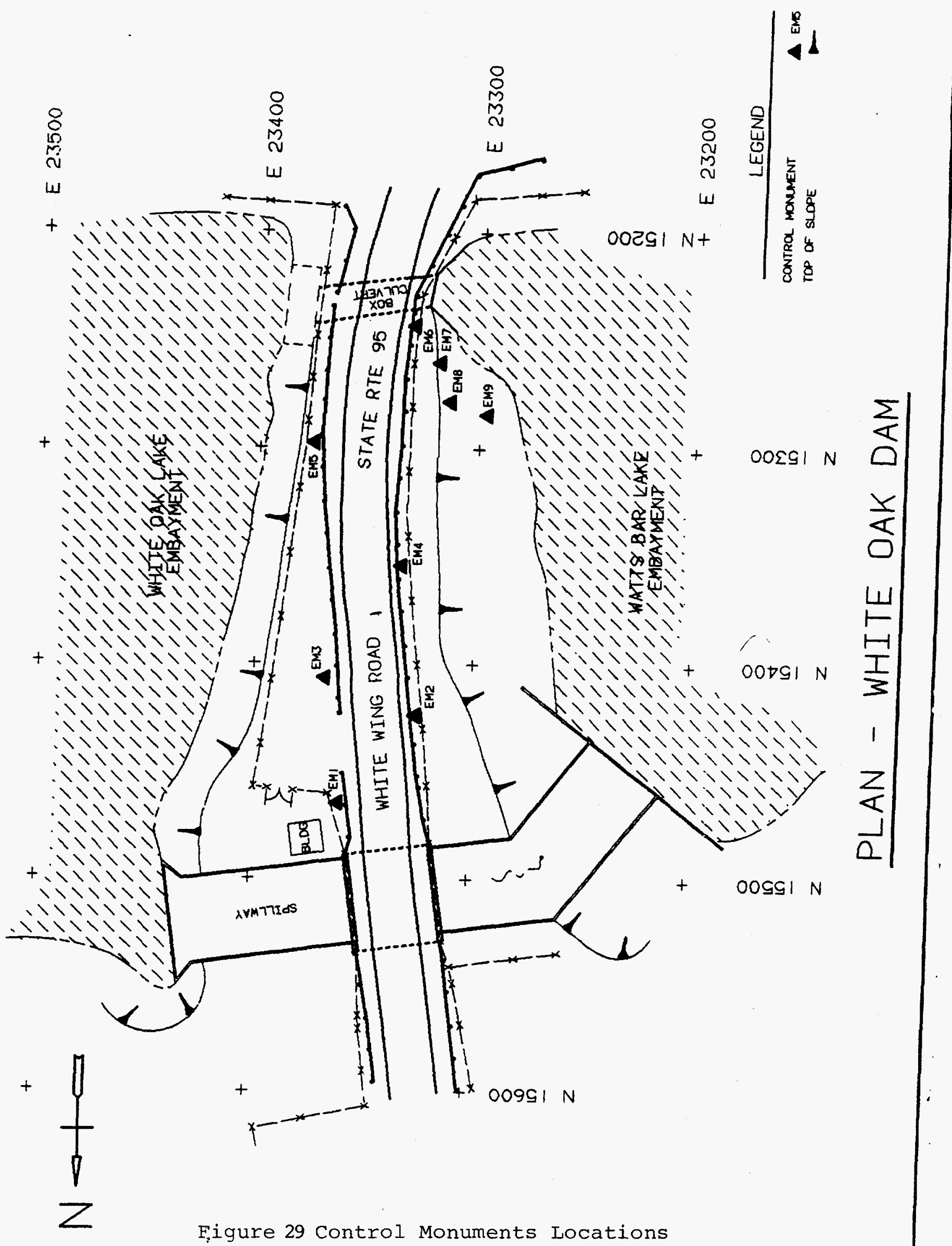




\subsection{CONCLUSIONS}

Based upon the results of the parametric study relating to the slope stability analysis, it can be concluded that the White Oak Dam is stable during the steady seepage, rapid drawdown, and seismic events discussed in section 10.1 .

Evaluation of the liquefaction potential discussed in Section 11.0 leads to the conclusion that the dam embankment and foundation soils are not susceptible to liquefaction. Therefore, the Evaluation Basis Earthquake will have no adverse effect on structural integrity of the White Oak Dam.

Ogden Environmental and Energy Services has checked and verified the calculations for the critical loading conditions and also performed a peer review of this report. Ogden has determined that the WOD is stable under the defined static and seismic loading conditions and the embankment materials are in general not susceptible to liquefaction.

The Management Plan for White Oak Dam has been adequately designed and implemented so that appropriate actions to prevent any progressive failure or to minimize the effects of failure can be taken.

The sediment control structure constructed at the mouth of the White Oak Creek Embayment (WOCE) would contain contaminated surface sediments in the lower WOCE and prevent the possibility of transporting the contaminated sediments into the Clinch River. 


\subsection{REFERENCES}

1. GEOTEK Report, "Evaluation of White Oak Dam" Geotek Project No. 79-687B, dated Nov. 14, 1979.

2. GEOLOGIC ASSOCIATES, EDGE, Report, "White Oak Dam Investigation" GA File No. 88X503, dated April 12, 1988.

3. Carpenter, J. R., "PCSTABLA User Manual" Report to U.S. Department of Transportation, Federal Highway Administration, Office of Research, Development and Technology, Washington, D.C., 1985.

4. Federal Energy Regulatory Commission, FERC 0119-2, "Engineering Guidelines for the Evaluation of Hydropower Projects", April 1991.

5. Tschantz, B. A., "Hazard Rating Evaluation of White Oak Dam", April, 1987.

6. Tschantz, B. A., "White Oak Creek" Hydrologic and Spillway Adequacy Analysis", August 15, 1987.

7. Tschantz, B. A., and Rghebi, W. A., "Hydrologic and Hydraulic Sensitivity Analysis for Supporting White Oak Dam Emergency Plan", May 1989.

8. Hatcher, R. D., et al., "Status Report on the Geology of the Oak Ridge Reservation", Oak Ridge National Laboratory, Martin Marietta Energy Systems, Inc., ORNL/TM-12074, October 1992.

9. Bolinger, G. A. "The Giles County, Virginia, Seismic Zone Configuration and Hazard Assessment, Proceedings, Earthquakes and Earthquake Engineering: The Eastern United States", Ann Arbor Science Publishers, September 1981.

10. "Seismic Hazard Evaluation for Department of Energy, Oak Ridge Reservations, Oak Ridge, Tennessee", Y/EN-4683, Prepared by Martin Marietta Energy Systems for the Department of Energy, September 30, 1992.

11. Memorandum from J. E. Beavers (MMES) to G. W. Benedict (DOE), "Oak Ridge ReservationRecommended Seismic Hazard", dated December 16, 1992.

12. Memorandum from G. W. Benedict (DOE) to Donald D. Cannon (MMES)," Implementation of New Seismic Hazard Levels for the Oak Ridge Reservation", dated September 1, 1993.

13. Kennedy, R. P., et al., "Design and Evaluation Guidelines for Department of Energy Facilities Subjected to Natural Phenomena Hazards, UCRL-15910", Prepared for the Office of the Assistant Secretary for Environment, Safety, \& Health, Office of Safety Appraisals, United States Department of Energy, June 1990.

14. DOE Standard 1024-92, "Guidelines for Use of Probabilistic Seismic Hazard Curves at Department of Energy Sites", U.S. Department of Energy, December 1992. 
15. Tennessee Valley Authority, "Correlation of Properties of Laboratory Compacted Soils" CE 84-28, December 12, 1984.

16. Drumm, Eric C., and Bennett, Richard M., "Slope Stability Analysis of White Oak Dam", April 21, 1988.

17. MMES, "Hazard Screening Application Guide", ES/CSET-2/R1, prepared for the U.S. Department of Energy, June 1992.

18. National Research Council, Liquefaction of Soils During Earthquakes, Report Prepared By the Committee On Earthquake Engineering Commission On Engineering and Technical Systems, National Academy Press, Washington, D.C., 1985.

19. Woodward-Clyde Consultants," Appendices: Subsurface Characterization and Geohydraulic Site Evaluation, West Chestnut Ridge Site," Report ORNL/Sub/83-64764/1\& V2", Oak Ridge National Laboratory, Oak Ridge, TN., 1983.

20. Seed, H. B., et al., "Evaluation of Liquefaction Potential Using Field Performance Data", ASCE Journal of Geotechnical Engineering, Vol. 109, No. 3.

21. Seed, H. B., et al., "Influence of SPT Procedures in Soil Liquefaction Resistance Evaluations", ASCE Journal of Geotechnical Engineering, Vol. 111, No. 12, 1985.

22. Liao, S. S. C, et al., "Overburden Correction Factors for SPT in Sand", ASCE Journal of Geotechnical Engineering, Vol. 112, No. 3, 1985.

23. Seed, H. B., et al., "Simplified Procedures for Evaluating Soil Liquefaction Potential", ASCE Journal of the Soil Mechanics and Foundations Division, Vol. 97, No. SM 9.

24. Letter dated August 30, 1988, from J. P. Witherspoon, ORNL Environmental and Health Protection Division, to H. Wayne Hibberts of U.S. DOE, Oak Ridge Operations.

25. Recommended Seismic Hazard Levels for the Oak Ridge, Tennessee; Paducah, Kentucky; Fernald, Ohio; and Portsmouth, Ohio, Department of Energy Reservations, K/BD-1025/R1, prepared by Union Carbide Corporation for the Department of Energy, December 1982.

26. Seismic Hazard Methodologies for the Central and Eastern United States, Technical Report NP4726-A, Electric Power Research Institute, July 1986, Revised 1988.

27. Bernreuter, D. L., et al., Seismic Hazard Characterization of 69 Plant Sites East of the Rocky Mountains, Technical Report NUREG/CR5250, UCID-21517, U.S. Nuclear Regulatory Commission, 1988.

28. MMES, "Management Plan for White Oak Dam" prepared by Teresa J. Pierce, January 1989.

29. Ogden Environmental and Energy Services, "Formal Inspection Report White Oak Dam", dated January 24, 1994, MMES Contract No. 88B99977V Release C-79. 
30. Environmental Consulting Engineers, Inc. Report, "Updated Hydrologic and Spillway Adequacy Analysis for White Oak Dam", November 29, 1993.

31. Ogden Environmental and Energy Service, memorandum to Syed B. Ahmed "White Oak Dam Stability Analysis Review and Comments", dated January 24, 1994.

32. MMES Internal Correspondence from Tom Purucker to Ray Gaddis, "Documentation of ORNL Facility Categorization for White Oak Lake Dam", dated August 31, 1993. 